\title{
Human Immunodeficiency Virus type 1 Endocytic Trafficking Through Macrophage Bridging Conduits Facilitates Spread of Infection
}

\author{
Irena Kadiu • Howard E. Gendelman
}

Received: 7 July 2011 / Accepted: 10 July 2011 /Published online: 26 July 2011

(C) The Author(s) 2011. This article is published with open access at Springerlink.com

\begin{abstract}
Bridging conduits (BC) sustain communication and homeostasis between distant tethered cells. These are also exploited commonly for direct cell-to-cell transfer of microbial agents. Conduits efficiently spread infection, effectively, at speeds faster than fluid phase exchange while shielding the microbe against otherwise effective humoral immunity. Our laboratory has sought to uncover the mechanism(s) for these events for human immunodeficiency virus type one (HIV-1) infection. Indeed, in our prior works HIV-1 Env and Gag antigen and fluorescent virus tracking were shown sequestered into endoplasmic reticulum-Golgi organelles but the outcomes for spreading viral infection remained poorly defined. Herein, we show that HIV-1 specifically traffics through endocytic compartments contained within $\mathrm{BC}$ and directing such macrophage-tomacrophage viral transfers. Following clathrin-dependent viral entry, HIV-1 constituents bypass degradation by differential sorting from early to Rab $11^{+}$recycling endosomes and multivesicular bodies. Virus-containing endocytic viral cargoes propelled by myosin II through $\mathrm{BC}$ spread to neighboring uninfected cells. Disruption of endosomal motility with cytochalasin $\mathrm{D}$, nocodasole and blebbistatin diminish intercellular viral spread. These data
\end{abstract}

Electronic supplementary material The online version of this article (doi:10.1007/s11481-011-9298-z) contains supplementary material, which is available to authorized users.

I. Kadiu $\cdot$ H. E. Gendelman $(\bowtie)$

Department of Pharmacology and Experimental Neuroscience, University of Nebraska Medical Center,

985800 Nebraska Medical Center,

Omaha, NE 68198-5800, USA

e-mail: hegendel@unmc.edu lead us to propose that HIV-1 hijacks macrophage endocytic and cytoskeletal machineries for high-speed cell-to-cell spread.

Keywords HIV-1 $\cdot$ Macrophage $\cdot$ Bridging conduits Tunneling nanotubes $\cdot$ Recycling endosomes .

Multivesicular bodies - Viral trafficking - Endocytic sorting . Lysosomes · Early endosomes · Motor proteins · Tubulin . Intercellular viral spread

\section{Introduction}

Retroviruses exploit subcellular structures to facilitate infection and evade immune surveillance. One of these is bridging conduits (BC), also referred to as tunneling nanotubes, that serve to tether distant cells (Gerdes et al. 2007; Xu et al. 2009). For mononuclear phagocytes (MP; monocytes, macrophages and dendritic cells) such conduits serve as cytoplasmic extensions that facilitate open-ended bidirectional exchange of cellular organelles and proteins amongst cells (Kadiu and Gendelman 2011). They also affect intercellular communication and can facilitate microbial infections (Chinnery et al. 2008; Onfelt et al. 2006; Xu et al. 2009; Kadiu and Gendelman 2011). The human immunodeficiency virus type one (HIV-1) may exploit such high-speed intercellular conduit communication links to accelerate spread of infection in lymphoid and neural tissues. Persistent viral replication would then ensue even during robust humoral immune responses (Gousset et al. 2009; Sowinski et al. 2008). HIV-1 Env, Gag, and Nef were identified in BC (Eugenin et al. 2009a, b; Sowinski et al. 2008; Xu et al. 2009). However, it remained unclear whether 
these represent mature HIV-1 surfing on the conduits or viral particulates sequestered into endocytic compartments (Eugenin et al. 2009a, b; Xu et al. 2009). More importantly, whether HIV-1's presence in BC facilitates infection or if the virus also engages in receptor-mediated "surfing" of conduits as seen for herpes simplex and murine leukemia viruses (HSV and MLV) (Dixit et al. 2008; Sherer et al. 2007) is not known. As for the latter, HSV and MLV bind to cell surface receptors then travel to neighboring cells where fusiondependent entry ensues. Here, lateral movement of the lipid bilayer coupled with internal actin retrograde flow facilitates intercellular viral transfers (Sherer and Mothes 2008). HIV-1 may also be sequestered into endosomes then travel in $\mathrm{BC}$ for intercellular spread. Recent evidence supports BC endocytic transport of HIV-1 and other pathogens. This is as follows. First, transfer of prions through conduits occurs within lysosomes (Gousset et al. 2009). Second, for HIV-1, it exploits endosome-BC trafficking pathways for its own sustenance. Viral assembly and budding occurs in intracellular vacuoles, late endosomes and multivesicular bodies (MVB) (Deneka et al. 2007; Orenstein et al. 1988). Macrophage endocytic compartments, such as late endosomes and MVB harbor infectious virus (Pelchen-Matthews et al. 2003; Sharova et al. 2005). Third, macrophage not T cell conduits support open-ended bidirectional exchange of endolysosomal compartments between tethered cells (Sowinski et al. 2008; Onfelt et al. 2006). Although HIV1-macrophage interactions were extensively investigated, the endocytic entry route for HIV-1 transfer was considered non-productive (Miyauchi et al. 2009; Uchil and Mothes 2009). The ability of macrophages to establish BC in vivo at times of robust antiretroviral immune responses is important as the process could be exploited to accelerate viral spread (Ciborowski and Gendelman 2006; Eilbott et al. 1989; Xu et al. 2009).

In attempts to better understand how HIV-1 may use BC for its spread, we studied the mechanism of intercellular viral transfer. Our prior works investigated trafficking through ER and Golgi networks. This was found necessary for HIV-1 cell-to-cell transfer but the pathways and regulatory processes remained ill defined (Kadiu and Gendelman 2011). Thus to this end, we used proteomic, immunologic and cell imaging assays to now demonstrate that HIV-1 is sequestered into clathrin-coated pits then sorted from early endosomes into non-degrading compartments. This included, but was not limited to, Rab11 recycling endosomes and MVB. Actomyosin networks regulated $\mathrm{BC}$ compartment mobility. The process occured 25 times faster than those recorded for "surfing" of retroviruses on filopodia (Sherer et al. 2007). Endosomes carry viral cargoes capable of viral gene expression. These data provide novel mechanisms of HIV-1 spread seen during host immune responses and show pivotal insights into what need be overcome in realizing an effective vaccine for viral elimination.

\section{Methods}

Antibodies (Abs) and reagents

Rabbit $\mathrm{Ab}$ to myosin II, charged MVB protein $4 \mathrm{a}$ (CHMP4a) and goat $\mathrm{Ab}$ to Rab11 were purchased from Santa Cruz Biotechnology (Santa Cruz, CA). Human Ab to Gag (recognizes Gag ${ }^{\text {Pr55 }}$, p24, p17, matrix), gp120, gp160, reverse transcriptase (RT), protease, integrase and the TZM-bl cell line were obtained through the NIH AIDS Research and Reference Reagent Program, Division of AIDS, NIAID, NIH (Bethesda, MD). Rabbit Abs to a- and $\beta$ tubulin and lysosome associated membrane protein 1 (LAMP1), as well as mouse and sheep Abs to HIV-1 gp120 were purchased from Novus Biologicals, LLC (Littleton, CO). Mouse Ab to LAMP1, early endosome antigen (EEA1), HIV-1 p24 and human leukocyte antigen (HLA-DR) and poly-D-lysine/fibronectin-coated LabTek chamber slides were purchased from BD Biosciences (San Diego, CA). Rabbit Abs to EEA1 and clathrin were purchased from Cell Signaling Technologies (Danvers, MA). Rabbit antimouse and mouse anti-goat secondary Abs conjugated to $6 \mathrm{~nm}$ gold particles were purchased from Electron Microscopy Sciences (Hatfield, PA). The following reagents were purchased from Invitrogen (Carlsbad, CA): beta-galactosidase ( $\beta$-gal) staining kit, Click-iT RNA Alexa Fluor 594 Imaging Kit, fluorescence insitu hybridization (FISH) Tag RNA multicolor kit, rhodamine phalloidin, phalloidin Alexa Fluor 488 and 647, transferrin (Tfn) conjugated to Alexa Fluor 594, anti-rabbit Alexa Fluor 488, 594,647, anti-mouse Alexa Fluor 488, 594, 647, anti-sheep Alexa Fluor 488, antihuman Alexa Fluor 488, 1,1'dioctadecyl-3, 3,3',3'tetramethylindodicarbocyanine perchlorate (DiD), 3,3'dioctadecyloxacarbocyanine perchlorate (DiO), ProLong Gold anti-fading solution with 4',6-diamidino-2phenylindole (DAPI). Dulbecco's Modified Medium (DMEM) high glucose with GlutaMax, Dulbecco's Phosphate Buffer Saline (DPBS), Penicillin/Streptomycin were purchased from Gibco/Invitrogen (Carlsbad, CA). Wortmannin, brefeldin A (BFA), blebbistatin (BBST), cytochalasin D (CD), nocodasole (Noc), dynasore, dithiothreitol (DTT), 3-[(3-cholamidopropyl)-dimethylammonio]-1-propane sulfonate (CHAPS), urea, thiourea, bovine serum albumin (BSA), triton-X and protease inhibitor cocktail were purchased from Sigma-Aldrich (Saint Louis, MO). COBAS Amplicor HIV-1 Monitor Test, v 1.5 was purchased from Roche Diagnostics Systems, Inc (Brunchburg, NJ). 
HIV-1 infection of human monocyte-derived macrophages (MDM)

Experiments with human peripheral blood mononuclear cells (PBMC) were performed in full compliance of the National Institutes of Health and the University of Nebraska Medical Center ethical guidelines. Monocytes from HIV-1, HIV-2 and hepatitis seronegative human donors were obtained by leukophoresis, and purified by countercurrent centrifugal elutriation (Gendelman et al. 1988). Experiments were performed utilizing primary human monocytes ( $N=50$ independent cultures). Monocytes were grown in suspension cultures using Teflon flasks. Cells were cultured in DMEM supplemented with $10 \%$ heat-inactivated human serum, 100 units of penicillin and $100 \mu \mathrm{g} / \mathrm{ml}$ of streptomycin, and $1,000 \mathrm{U} / \mathrm{ml}$ highly purified recombinant macrophage colony stimulating factor (MCSF), a generous gift by Pfizer, Inc., (Cambridge, MA). Cells were maintained at $37^{\circ} \mathrm{C}$ in a $5 \% \mathrm{CO}_{2}$ atm for $7 \mathrm{~d}$ to permit for differentiation into MDM. At day 7, MDM were exposed to the macrophage-tropic strain $\mathrm{HIV}-1_{\mathrm{ADA}}$ at a multiplicity of infection (MOI) of 0.5 infectious viral particles/cell for $24 \mathrm{~h}$. Prior to seeding in mixed cultures (infected and uninfected MDM), HIV-1 infection was assessed by flow cytometry analysis of cells stained for HIV-1 p24 FITC (Kadiu et al. 2007).

Virus isolation and labeling techniques

Virus isolation was performed as described (Kadiu et al. 2007). Enriched HIV-1 was labeled with $2 \mu \mathrm{M}$ DiO or DiD for $20 \mathrm{~min}$ in phosphate buffered saline (PBS) at $37^{\circ} \mathrm{C}$. Virus was resuspended in PBS and centrifuged twice at $100,000 \times$ g on a $20 \%$ sucrose cushion to remove unbound dye. For intercellular tracking of virus, labeled HIV-1 was resuspended in culture medium and added to adherent MDM in mixed culture prior to time-lapse microscopy.

Time-lapse confocal imaging

MDM grown in suspension were labeled with $2 \mu \mathrm{M}$ DiD (infected) and $\mathrm{DiO}$ (uninfected) for $20 \mathrm{~min}$ at $37^{\circ} \mathrm{C}$ in $5 \%$ $\mathrm{CO}_{2}$. Unbound dyes were removed by washing three times with DMEM supplemented with 10\% heat-inactivated human serum at $37^{\circ} \mathrm{C}$. Cells were seeded on $35-\mathrm{mm}$ glass-bottom plates (MatTek Corporation, Ashland, MA) in mixed cultures and subjected to live imaging at $37^{\circ} \mathrm{C}$ and $5 \% \mathrm{CO}_{2}$. Images were taken in $5 \mathrm{~s}$ time intervals, using a $100 \times$ oil immersion objective attached to a Nikon TE2000U utilizing a Swept Field Confocal microscope (Nikon, Tallahassee, FL). Brightness and contrast of the movies were adjusted to improve visibility of particles associated with BC. Imaging of particle movement in BC (from cell body to cell body) was performed manually using the NSI
Elements software (Nikon). Particles with trajectories shorter than 10 frames and moving out of focus during recording were excluded from the tracking analysis.

Fluorescence in-situ hybridization

Alexa Fluor 488-labeled linearized Gag-Pol probes (2.2 kb; Hind III-Kpn; Lofstrand Labs Limited, Gaithersburg, MD) were generated using FISH Tag RNA Multicolor Labeling Kit (Invitrogen). Probe labeling and in-situ hybridization were performed per manufacturer's instructions.

HIV-1 endocytic entry and intracellular trafficking

Adherent MDM were washed three times and incubated with serum free medium for $30 \mathrm{~min}$. Cells were incubated for $30 \mathrm{~min}$ with either $100 \mu \mathrm{M}$ of dynasore in serum-free medium or left untreated. Cells were washed once with serum-free media, then DiD-labeled HIV-1 together with fresh inhibitors was added to MDM for $3 \mathrm{~h}$ at $37^{\circ} \mathrm{C}$. Cells were washed three times in PBS, mechanically detached using cell lifters (Thermo-Fisher Scientific, Waltham, MA), fixed in 4\% paraformaldehyde (PFA) for $30 \mathrm{~min}$ and analyzed for viral uptake by flow cytometry. Data was acquired on a FACSCalibur flow cytometer (BD Biosciences) using CellQuest Software (BD Biosciences). For disruption of endocytic sorting, MDM were plated for $3 \mathrm{~h}$ in mixed culture, followed by treatment with $1 \mathrm{mM}$ wortmannin and $0.5 \mathrm{mM}$ BFA for $3 \mathrm{~h}$. Cells were washed three times with PBS and fixed with 4\% PFA for $30 \mathrm{~min}$. Immunostaining and confocal analyses followed as described below.

\section{Disruption of HIV-1 transport}

For disruption of endosome motility, uninfected and HIV-1infected MDM were labeled with $\mathrm{DiO}$ (as described above) and plated in mixed culture for $3 \mathrm{~h}$ to allow for contact establishment. Cells were exposed to DiD-labeled virus for $1 \mathrm{~h}$ and then treated with $50 \mu \mathrm{M}$ CD, Noc, or BBST for 10 min. Inhibitors were removed, and BC-dependent cellto-cell endosome transfer was determined by time-lapse confocal microscopy and particle tracking analyses. A group of inhibitor-treated and untreated unlabeled cells in mixed culture were stained for HIV-1 Env and Gag and myosin II and imaged by confocal microscopy.

Imaging of recycling compartments

MDM in mixed culture were seeded onto poly-D-Lysinecoated chamber slides for $3 \mathrm{~h}$ devoid of human serum. Cells were incubated with $1 \mu \mathrm{M}$ Alexa 594-Tfn or DiO-labeled HIV-1 for $1 \mathrm{~h}$. Non-internalized particulates were removed 
by three sequential washes with PBS. Cells were fixed with $4 \%$ PFA and imaged using the $63 \times$ oil lens of a LSM 510 confocal microscope (Carl Zeiss MicroImaging, LLC, Thornwood, NY).

\section{Metabolic labeling of RNA and proteins}

Metabolic labeling and detection of newly synthesized RNA was performed using Click-It RNA labeling kit per manufacturer's instructions (Invitrogen). Metabolic incorporation of 5-ethynyl uridine (EU) was extended to $24 \mathrm{~h}$. Additional immunostaining and imaging of the MDM was performed as described below.

\section{Immunocytochemistry and confocal microscopy}

For immunofluorescence staining, cells were washed three times with PBS and fixed with 4\% PFA at room temperature for $30 \mathrm{~min}$. Cells were treated with blocking/ permeabilizing solution ( $0.1 \%$ Triton, $5 \%$ BSA in PBS) and quenched with $50 \mathrm{mM} \mathrm{NH} \mathrm{Nl}_{4} \mathrm{Cl}$ for $15 \mathrm{~min}$. Cells were washed once with $0.1 \%$ Triton in PBS and sequentially incubated with primary and secondary $\mathrm{Ab}$ at room temperature. For MDM stained with multiple antibodies, non-specific cross binding of secondary Abs was tested prior to immunostaining. Use of secondary antibodies originating or recognizing the same hosts was avoided. Slides were covered in ProLong Gold anti-fading reagent with DAPI and imaged using a $63 \mathrm{X}$ oil lens in a LSM 510 confocal microscope (Zeiss).

\section{Enrichment of macrophage protrusions and proteomic} characterization

Enrichment of the macrophage protrusions was performed as described with some modifications (Beckner et al. 2005). Prior to $\mathrm{BC}$ collection, cells were maintained in Teflon flasks and media was changed every $2 \mathrm{~d}$ to maintain the infected MDM cultures metabolically stable. Cells were then seeded on a $9 \mathrm{~mm}$ thick, $3-\mu \mathrm{m}$ pore polycarbonate filter of a Boyden chemotaxis apparatus (NeuroProbe, Gaithersburg, MD) and maintained at $37^{\circ} \mathrm{C}$ in a $5 \% \mathrm{CO}_{2}$ tissue culture incubator for $3 \mathrm{~h}$. Prior to harvesting of $\mathrm{BC}$, each filter was first immersed in $100 \%$ methanol for $15 \mathrm{~s}$ then placed with migrated cell materials (attached to the undersurface of the filter) on a glass slide. Each filter was firmly pressed against a glass slide to promote adherence of migrated cellular processes. Cell bodies were wiped from the filter top, and the filter was then gently peeled off the slide with forceps. The processes were solubilized in lysis buffer $\mathrm{pH} 8.5[30 \mathrm{mM}$ Tris $\mathrm{HCl}, 7 \mathrm{M}$ urea, $2 \mathrm{M}$ thiourea, $4 \%$ $(w / v)$ CHAPS, $20 \mathrm{mM}$ DTT and $1 \mathrm{X}$ protease inhibitor cocktail by pipeting. The remainder of the lysate was allowed to crystallize on slides and harvested using razor blades. One-dimensional gel electrophoresis, mass spectrometry and database searches were performed as described (Kadiu et al. 2009).

Scanning and transmission electron microscopy

MDM were seeded in mixed culture on Thermanox coverslips (Thermo-Fisher Scientific) and allowed to establish BC for $24 \mathrm{~h}$. Cells were then washed with PBS and fixed in $2 \%$ glutaraldehyde and 2\% PFA in $0.1 \mathrm{M}$ Sorensen's phosphate buffer (SPB). Post-fixation cells were exposed to $1 \%$ osmium tetraoxide for $30 \mathrm{~min}$ and dehydrated at $50 \%, 70 \%, 90 \%, 95 \%$, and $100 \%$ ethanol for $10 \mathrm{~min}$. Samples for transmission electron microscopy (TEM) were embedded in Araldite. Coverslips were removed and areas of the cell culture were selected for ultrathin (60 $\mathrm{nm}$ thick) sectioning. Cells were sectioned on the plane of the colony and in cross sections. Sections were stained with uranyl acetate and lead citrate and observed in a Tecnai G2 Spirit TEM (FEI Company, Hillsboro, OR). Samples for scanning electron microscopy (SEM) were critical point dried, mounted on specimen stubs and sputter coated with $40 \mathrm{~nm}$ of gold/palladium. Samples were observed with FEI Quanta 200 SEM (FEI Company) operated at $25 \mathrm{kV}$. For immunogold labeling, MDM in mixed infected and uninfected cultures were fixed with $2 \%$ glutaraldehyde and $2 \%$ PFA in $0.1 \mathrm{M}$ SPB for $24 \mathrm{~h}$. Cells were washed in PBS and permeabilized with $0.5 \%$ Triton-X and $3 \%$ BSA in PBS for $24 \mathrm{~h}$ then incubated with primary $\mathrm{Ab}$ for $4 \mathrm{~h}$ at ambient temperature. Between incubation with gold conjugated $\mathrm{Ab}$ $(6 \mathrm{~nm})$ for $2 \mathrm{~h}$, MDM were washed three times in $0.5 \%$ Triton-X and 3\% BSA. Cells were then post-fixed with $2 \%$ glutaraldehyde and $2 \%$ PFA in $0.1 \mathrm{M}$ SPB and processed for TEM as described above.

Enrichment of endocytic compartments

Immune isolation of endocytic compartments was performed as previously described, with some modifications (Basyuk et al. 2003). MDM $\left(400 \times 10^{6}\right.$ cells) were seeded in mixed cultures (uninfected and infected MDM at equal ratios) and allowed to establish $\mathrm{BC}$ for $24 \mathrm{~h}(>90 \%$ of cell population connected by BC). Cells were scraped in homogenization buffer (10 mM HEPES$\mathrm{KOH}, \mathrm{pH} 7.2,250 \mathrm{mM}$ sucrose, $1 \mathrm{mM}$ EDTA, and $\left.1 \mathrm{mM} \mathrm{Mg}(\mathrm{OAc})_{2}\right)$ and disrupted by 15 strokes in a dounce homogenizer. Nuclei and unbroken cells were removed by centrifugation at $800 \times \mathrm{g}$ for $15 \mathrm{~min}$ at $4^{\circ} \mathrm{C}$. Supernatant was layered on a $20 \%$ sucrose cushion and centrifuged at $100,000 \times \mathrm{g}$ for $1 \mathrm{~h}$. The pellet was resuspended in $40 \%$ sucrose, $10 \mathrm{mM}$ imidazole solution 
pH 7.4 followed by layering on $60 \%, 35 \%, 20 \%$ and $10 \%$ sucrose gradient and centrifugation at $100,000 \times \mathrm{g}$ at $4{ }^{\circ} \mathrm{C}$ for $1 \mathrm{~h}$. The interfaces between $10 \%$ and $20 \%$ and $40 \%$ and $35 \%$ sucrose bands containing enriched endocytic compartments were collected and washed in PBS using ultracentrifugation at $100,000 \times$ g. Pellets were then incubated with protein $\mathrm{A} / \mathrm{G}$ paramagnetic beads $(20 \mu \mathrm{l}$ of slurry; Millipore) previously conjugated to endosome $\mathrm{Ab}$ $(10 \mu \mathrm{g}$ of $\mathrm{Ab})$ for $12 \mathrm{~h}$ at $4^{\circ} \mathrm{C}$. Endocytic compartments were washed and collected on a magnetic separator (Invitrogen). For TEM imaging endocytic compartments were fixed in $2 \%$ glutaraldehyde and $2 \%$ PFA in $0.1 \mathrm{M}$ SPB for $3 \mathrm{~h}$ and then isolated by magnetic separation. The bead-endosome pellet was then covered in agar and processed for TEM as described above.

\section{Reporter cell line}

TZM-bl cells were cultured in DMEM supplemented with $10 \%$ fetal bovine serum, 100 units of penicillin and $100 \mu \mathrm{g} /$ $\mathrm{ml}$ of streptomycin. Cells were allowed to reach $70 \%$ confluence, then detached by $25 \mathrm{mM}$ trypsin/EDTA for $5 \mathrm{~min}$ at $37^{\circ} \mathrm{C}$. Detached cells were cultured and allowed to recover in 4 well poly-D-lysine LabTech chamber slides for $2 \mathrm{~d}$ or until they reached $40 \%$ confluence. Protein A/G paramagnetic beads bound to isotype control Abs or endocytic compartments $(20 \mu \mathrm{l}$ of slurry/500 $\mu \mathrm{l}$ of medium/well), and HIV-1 Tat protein $(2 \mu \mathrm{M})$ were reconstituted in supplemented DMEM and added to cells. Replicate wells were pre-treated with $100 \mu \mathrm{M}$ Efavirenz (EFZ) for $24 \mathrm{~h}$ prior to exposure to endocytic compartments. Chamber slides were placed on a plate magnet $(\mathrm{Oz}$ Biosciences/Boca Scientific, Boca Raton, FL) for $24 \mathrm{~h}$ at $37^{\circ} \mathrm{C}$ in $5 \% \mathrm{CO}_{2}$ after addition of endocytic compartmentbead conjugates. The magnet was removed and cells were washed three times with PBS and maintained in culture medium for additional $48 \mathrm{~h}$ prior to $\beta$-gal detection (per manufacturer's instructions). Bright field images were acquired using a Nikon Eclipse TE300 microscope (Nikon).

\section{Quantitation of endosome viral load}

RNA viral load for EEA1 ${ }^{+}, \mathrm{Rab}_{1} 1^{+}, \mathrm{CHMP}^{+}$and LAMP1 ${ }^{+}$ immune-isolated compartments was measured using COBAS Amplicor HIV-1 Monitor Test, v 1.5 and COBAS AmpliPrep Instrument for automated specimen processing (Roche Diagnostics) per manufacturer's instructions.

Colocalization tests and statistical analyses

Quantitation of immunostaining and Pearson's colocalization coefficients was performed with ImageJ software, utilizing JACoP plugins (http://rsb.info.nih.gov/ij/plugins/track/jacop. html) (Bolte and Cordelieres 2006). Comparison was performed on 7-10 sets of images (whole cells) acquired with the same optical settings. To improve visibility of subcellular compartments in the $\mathrm{BC}$, brightness and contrast settings were changed for the entire image in select images using Adobe Photoshop. Graphs and statistical analyses were generated using Excel and GraphPad Prism. Two-tailed Student's $t$-tests were used for all data and the error bars are shown as \pm S.E.M., unless noted otherwise. Results were considered significant at $P<0.05$.

\section{Results}

BC speeds communication between MDM

We first assessed the abilities of $\mathrm{BC}$ to affect exchange between infected and uninfected MDM. This was done first by measures of the dynamics of contact formation between cells. Cells were propagated in suspension Teflon cultures in complete media containing MCSF. Half of the cells were infected with $\mathrm{HIV}-1_{\mathrm{ADA}}$ at a MOI of 0.5 infectious viral particles/cell and the second half were uninfected. After $7-10$ days, greater than $96 \%$ of cells within the infected cultures were HIV-1p24 positive (as assayed by flow cytometry, Fig. 1a). At that time, the infected and uninfected MDM were mixed at equal ratios. These were defined as mixed cultures. BC formation between infected and uninfected cells was confirmed by confocal imaging of mixed cell cultures immunostained for HIV-1 Env glycoproteins (gp120/gp160) and microtubules (alpha/beta tubulin). Images showed cellular protrusions connecting HIV-1 $\mathrm{Env}^{+}$(red) to Env- (green) uninfected MDM (Fig. 1b, arrows). BC frequency was measured in mixed cell cultures at 30,60 and $180 \mathrm{~min}$ and was time dependent. Number of cells connected by BC increased significantly at $60(P<0.0001)$ and $180 \mathrm{~min}(P=$ 0.0077 ; Fig. 1c). At $180 \mathrm{~min}$ BC displayed tubular morphologies (Fig. 1d, arrows). Unlike $\mathrm{T}$ cell conduits that form as two touching cells which move away from each other (Sowinski et al. 2008), macrophage BC extend from one cell to their target and display three-dimensional flagellum-like movements (Movie S1). Their length and diameter average $110 \pm 57 \mu \mathrm{m}$ and $7 \pm 4 \mu \mathrm{m}$ (mean \pm S.D., $n=238$ cells; Fig. 1e,f). BC were distinct from nontethered protrusions used by macrophages for cell migration, which include bulbous lamellipodia (Fig. S1A) or thin and short filopodia (Movie S2) (Lundquist 2009; Vonna et al. 2007). To best visualize BC-mediated communications, uninfected and infected MDM were labeled with $\mathrm{DiO}$ (green) and $\mathrm{DiD}$ (red) lipophilic dyes, respectively. Such dyes are sequestered into endocytic compartments and can be used to measure long-term endocytic trafficking 
(Rustom et al. 2004; Sowinski et al. 2008). To accomplish this task, DiO- and DiD-labeled cells were removed from suspensions and plated in mixed culture. Time-lapse images at $30 \mathrm{~min}$ during adherence demonstrated that virus-infected MDM readily generated BC. Particle tracking showed that endosome transfer through $\mathrm{BC}$ occurred immediately after cell contact at $1.0 \pm 0.7 \mu \mathrm{m} \cdot \mathrm{s}^{-1}$ (mean \pm S.D., $n=80$ particles; Fig. 1g,h). MDM in "pure" infected and in mixed infected and uninfected cultures displayed increased intra- and intercellular endocytic traffic when compared to uninfected cells alone (Movies S3-S5). Since both BC and secreted vesicles contribute to intercellular communication, lipid transfer activity was measured in the presence (adherent cultures) and absence (suspension cultures) of BC (Simons and Raposo 2009). Overall lipid transfer peaked at $180 \mathrm{~min}$, with $42 \%$ of the cells displaying dual dye labeling. Of these only $19 \%$ acquired dual fluorescence through $\mathrm{BC}$. Together these data demonstrate that macrophage $\mathrm{BC}$ connect infected to uninfected cells.

\section{HIV-1 constituents in BC}

We next asked whether HIV-1 constituents are present in the conduits. This is a seemingly important question for viral spread and likely present as BC facilitate transfer of cellular material between infected and uninfected MDM. Punctate distribution of HIV-1 RNAs in BC and cell body was visualized by fluorescence in situ hybridization. This was visualized by HIV-1 Gag-Pol probes labeled with Alexa Fluor 488 (Fig. 2a, inset boxes 1 and 2). Whole cell and viral RNA metabolically labeledwith 5-ethynyl uridine-Alexa Fluor 594 was co-distributed with Env, Gag and RT within large compartments in BC (Table S1). Env, capsid (Gag including Gag $^{\text {Pr55 }}$, p24, p17, matrix), RT, integrase, protease, Tat and Vif were readily identified in $\mathrm{BC}$ (Fig. 2b-h). Interestingly, such BC-associated viral constituents appeared as large particulates $(0.5-2.5 \mu \mathrm{m}$ in diameter) and were confined to the $\mathrm{BC}$ cortical actin (phalloidin-Alexa Fluor488; Fig. 2e-h; Table S1). These data demonstrate that HIV-1 constituents (HIV-1 proteins and viral RNA) are present in macrophage BC.

\section{HIV-1 is sequestered into endosomes}

The presence of HIV-1 Env-CD4 complexes in the conduits would suggest that virus exploits receptordependent "surfing" on BC to reach neighboring target cells (Martin and Sattentau 2009; Sowinski et al. 2008). We then asked whether such a manner of viral transport would require mature progeny HIV-1 on the exterior of BC. Thus, the presence of CD4-Env complexes associated with macrophage conduits was assessed. Confocal imag-
Fig. 1 BC sustain communication between uninfected and infected MDM. a Assessment by flow cytometry of HIV-1 infection in single culture MDM. b Formation of BC between infected and uninfected MDM labeled for HIV-1 envelope (red) and microtubules (green). Observe presence of HIV-1 Env along the conduit (scale bars, $10 \mu \mathrm{m}$, inset, $5 \mu \mathrm{m}$ ). c Frequency of BC formation in MDM uninfected, infected and mixed cultures (equal ratios of uninfected and infected MDM) at 30,60 and $180 \mathrm{~min}$ in adherence ( $n=450$ cells/group, error bars \pm S.E.M). Data are representative of five independent experiments. d Bright field images of conduits connecting MDM in mixed culture. Arrows indicate tethering sites (scale bar, $10 \mu \mathrm{m})$. e, f Frequency of conduit length and diameter observed in MDM mixed populations $(n=238$ cells). g Time-lapse confocal images showing contact establishment and lipid transfer through BC from infected (DiD-labeled, red) to uninfected (DiO-labeled, green) MDM. h Velocity of lipid transfer through the BC. Graph reflects average velocity values recorded at each time point for 80 particles tracked along the BC (error bars \pm S.E.M.). i Intercellular transfer activity in mixed MDM in presence (adherent cultures) and absence (suspension cultures) of conduits. Ratios of cells affected by this process over time (yellow, upper right quadrants) compared to the overall red (DiD-labeled infected MDM, upper left quadrants) and green populations (DiO-labeled, uninfected MDM, lower right quadrants) are shown in bold

ing of MDM identified large particulates $(0.5-2 \mu \mathrm{m})$ of $\mathrm{CD}^{+}{ }^{+}$and $\mathrm{Env}^{+}$in the conduits (Fig. S2A, inset boxes 1 and 2). SEM revealed BC tubular morphologies and its plasma membrane sheathing of vesicle-like compartments (Fig. 3a,b). TEM revealed heterogeneous populations of $\mathrm{BC}$ containing endocytic vesicles varying in coating, size and electron densities (Fig. 3c, inset 1 and arrows). Plasma membrane microvesicles were on the surface of the $\mathrm{BC}$ (Fig. S2B). Fifty-five cross-sections (60 $\mathrm{nm}$ thick) of MDM in mixed cultures were generated $(n=5$ independent experiments). Mature virions were identified in the extracellular space of ten sections (Fig. S2C, inset 1, red arrow), however none were observed anchored to the $\mathrm{BC}$ plasma membrane ( $n=70$ conduits imaged). Disruption of $\mathrm{BC}$ using microflament and microtubule inhibitors $\mathrm{CD}$ and Noc, respectively suppressed productive infection at similar levels to the protease inhibitor Atazanavir (ATV). Treatment with neutralizing antibodies did not alter levels of HIV-1 infection or its presence in the BC (Fig. S2D). On the contrary early endosomes containing anti-Env $\mathrm{Ab}$ and $\mathrm{CD} 4$ were readily identified in the $\mathrm{BC}$ (Fig. S2E, F). Interestingly, inhibition of clathrindependent endocytosis blocked uptake of fluorescently labeled HIV-1 (Fig. S2G). HIV-1 and CD4 were present within large clathrin ${ }^{+}$compartments in the cell body and BC (Fig. S2H, arrows). TEM imaging of immunogoldlabeled mixed MDM cultures showed Gag $\left(\mathrm{Gag}^{\mathrm{Pr} 55}, \mathrm{p} 24\right.$, p17, matrix) punctate staining of endocytic vesicles (arrows indicate gold-laden compartments). In some instances, capsid-like morphologies were observed within these same structures (Fig. 3d, blue arrow). These data, taken together, suggested that BC-associated HIV-1 was sequestered into endocytic compartments. 
A

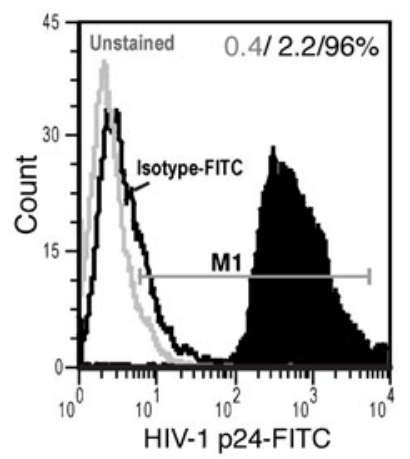

D

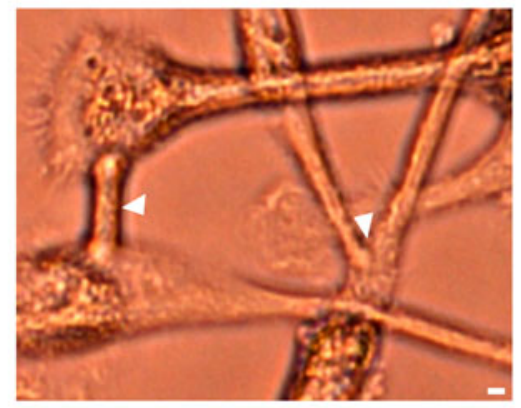

G

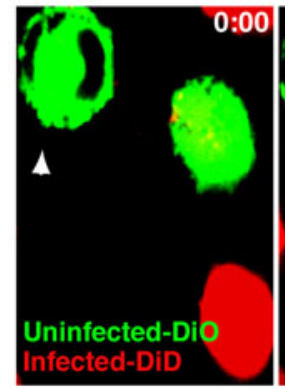

B

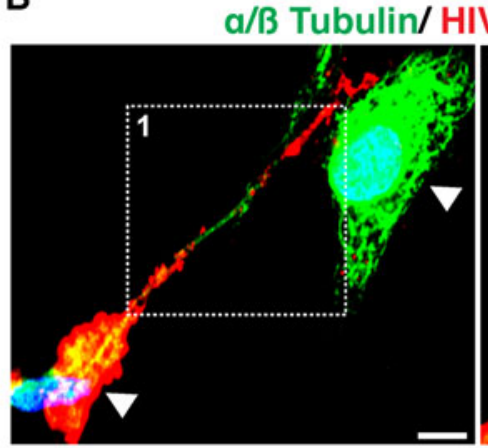

E

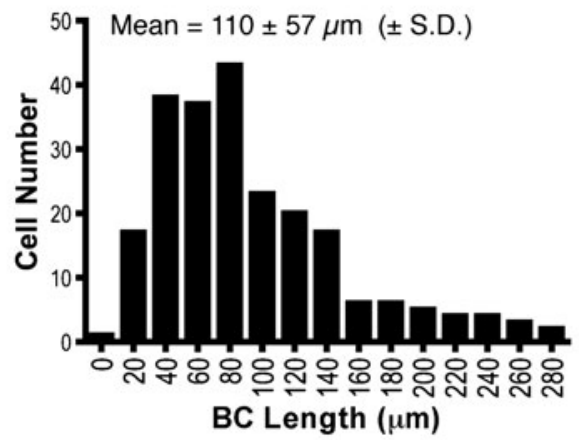

C

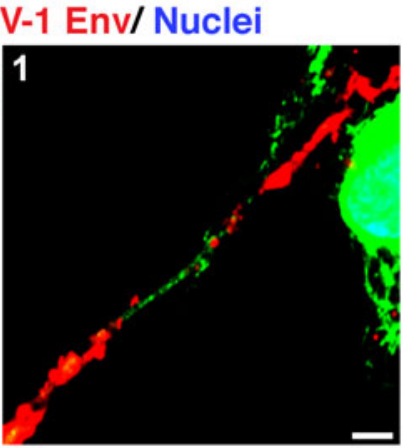

$\mathbf{F}$
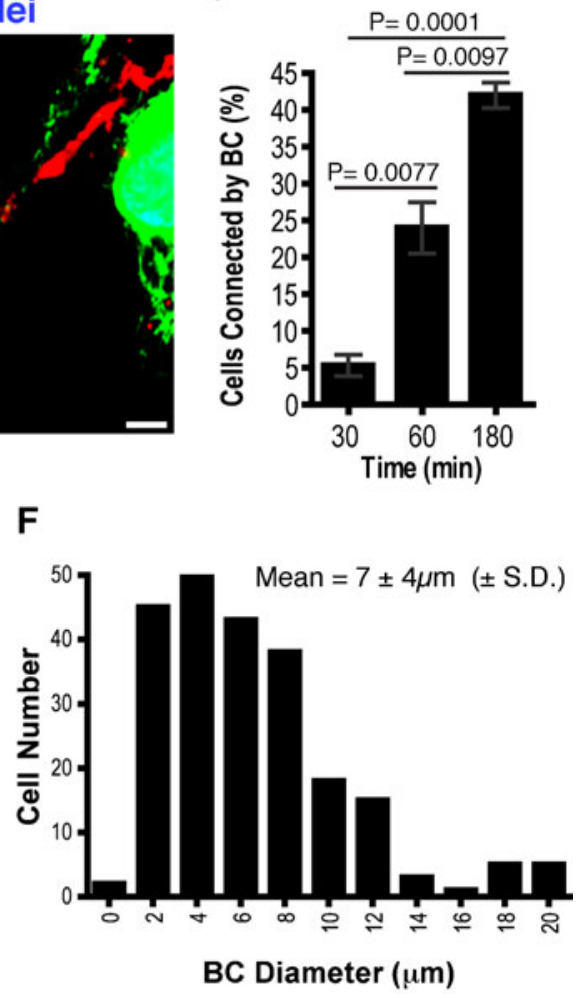

H

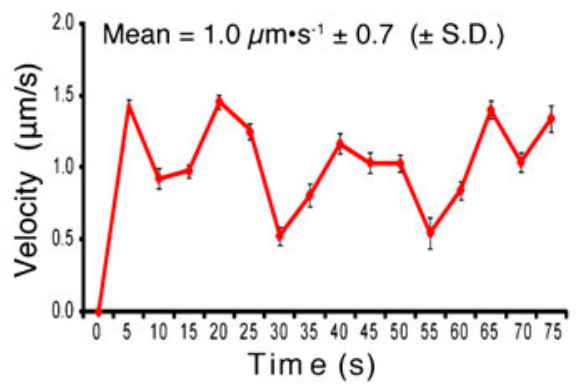

I

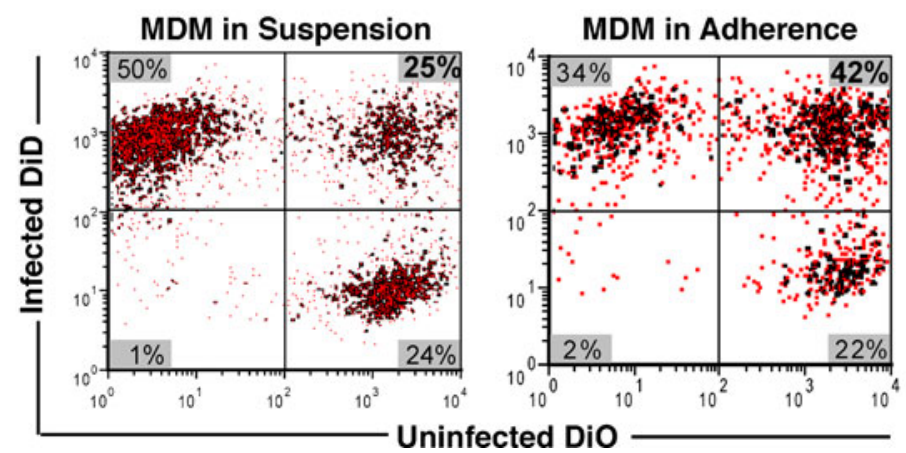

Characterization of the $\mathrm{BC}$ endocytic transport machinery

We next sought to identify the intercellular transport compartments for HIV-1. To this end, we characterized the proteome of the macrophage conduits. To mimic formation of BC in mixed cultures, HIV-1-infected MDM were seeded on a filter membrane separating them from the lower chamber of a Boyden chemotaxis apparatus containing uninfected MDM-conditioned medium (Fig. S3A-B). Figure 3e shows infected MDM extending their processes 

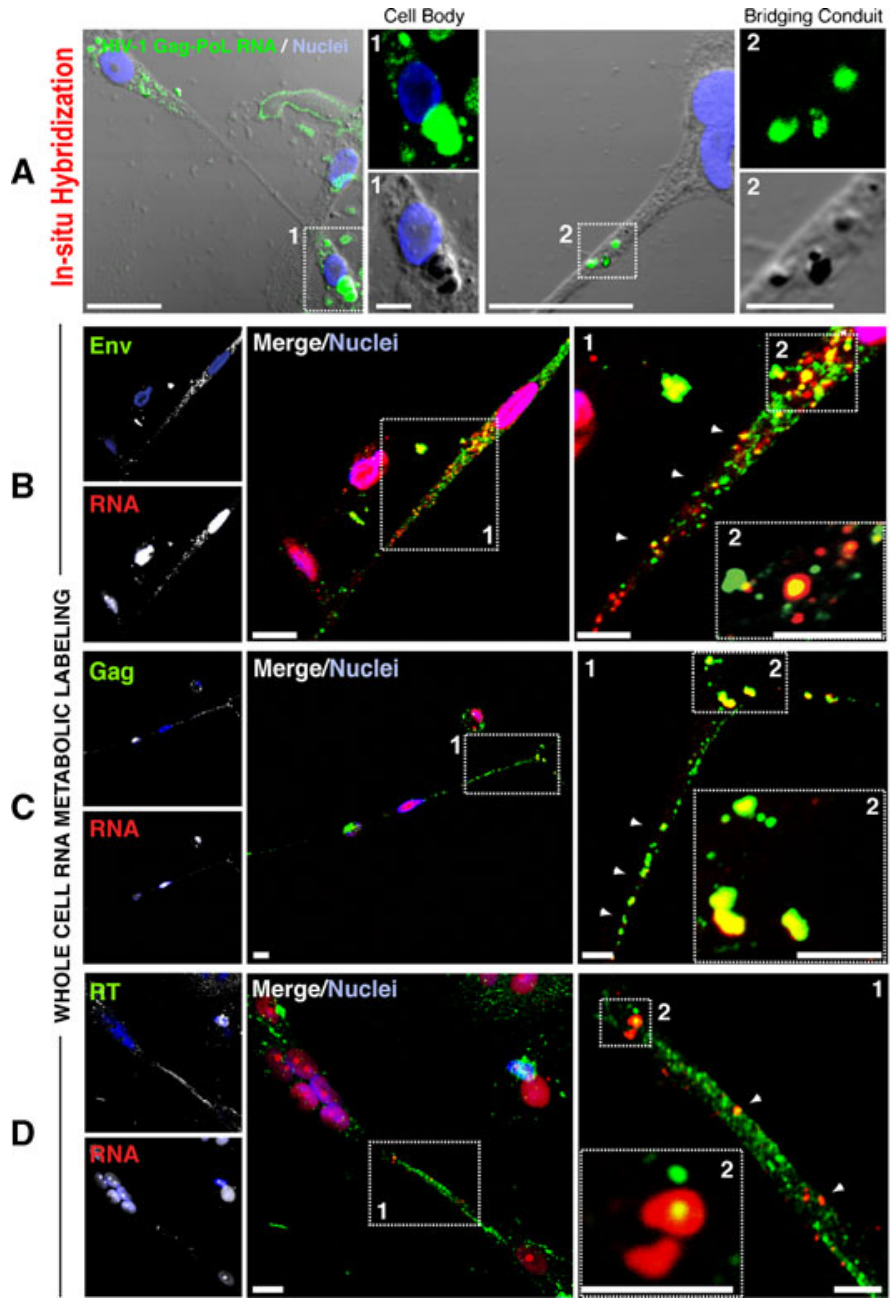

Fig. 2 HIV-1 constituents are identified in the BC. a Detection by fluorescence in-situ hybridization of viral RNA using Alexa Fluor488labeled HIV-1 Gag-Pol probes (green). Confocal and differential interference contrast (DIC) images show presence of HIV-1 RNA in the cell body and conduits (insets 1 and 2). b-d HIV-1 Env (green), Gag (Gag ${ }^{\text {Pr55 }}$, p24, p17, matrix; green), RT and RNA Alexa Fluor594 (red, metabolically-labeled with 5-ethynyl uridine) are readily visible

through filter pores unto the lower chamber (arrows). Protrusions were mechanically detached from the cell bodies and visualized by bright field and confocal microscopy (Fig. S3C, D). Proteomic characterization of enriched conduits identified early, late and recycling endosomes, MVB, lysosomes and actin-binding proteins. Regulators of endocytic sorting, including Rab GTP-ases (Rab1, 2, 5, 7a, 11a) and late endosome-lysosomal markers (annexin II and IV, MHCI, MHCII, as well as ubiquitin and cathepsin isoforms) (Jouve et al. 2007; Zerial and McBride 2001) accounted for $13 \%$ of the conduit proteome (Fig. 3f; Table S2). Proteins driving endosome movement and regulators of actin stress fibers such as myosin motor proteins IC, II, light chain (LC) 6 and heavy chain (HC) 9, together with other actin-binding proteins represented $14 \%$ of the overall

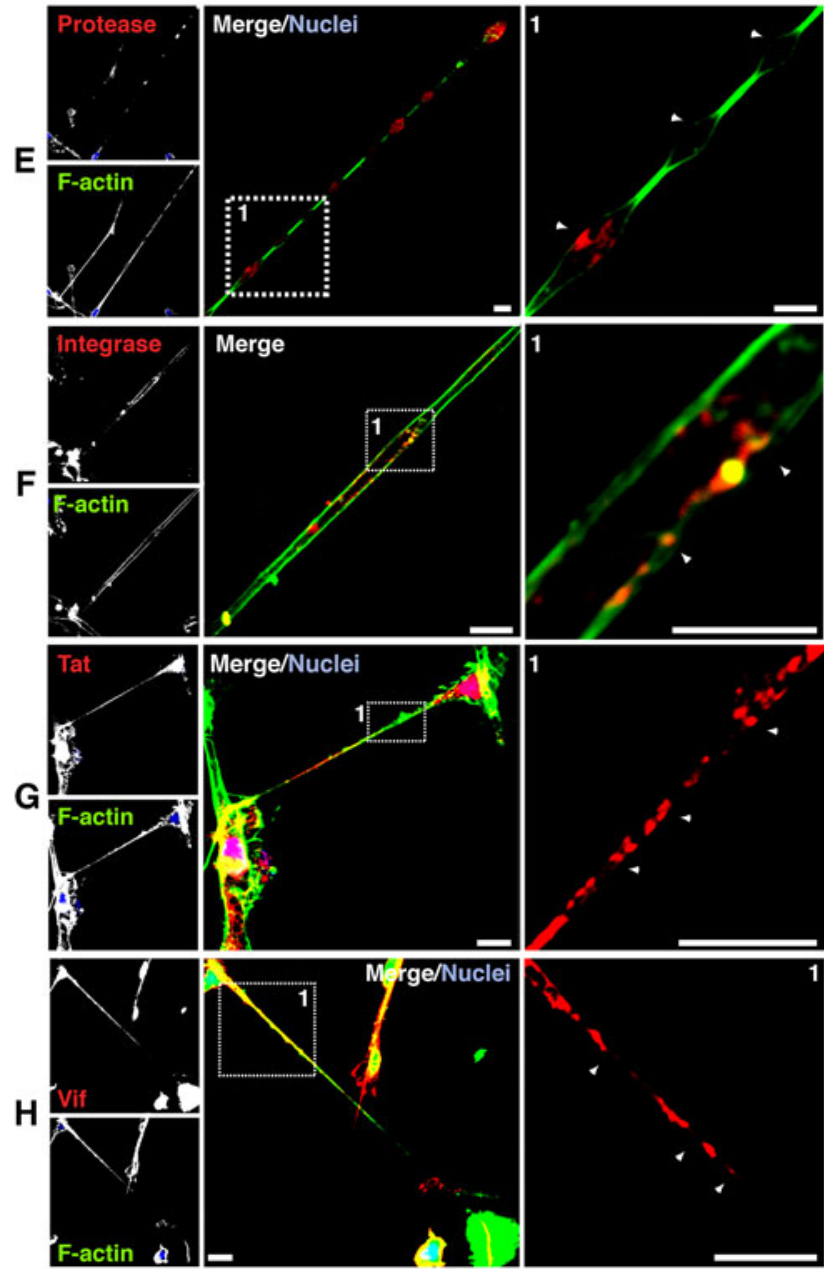

in the conduits. (Refer to Table S1 for newly synthesized RNA and viral protein co-localization coefficients). e-h HIV-1 protease (red), integrase (red), Tat and Vif (red) are present in the BC. Staining for cortical actin (phalloidin-Alexa Fluor 488) and nuclei (DAPI, blue) was performed to distinguish MDM connected by the conduits from polarized single cells (scale bar, $10 \mu \mathrm{m}$; inset, $5 \mu \mathrm{m}$ )

proteome, while HIV-1 proteins accounted for $4 \%$. These findings indicated that active endocytic transport of HIV-1 occurred in the macrophage conduits.

Endosomes, HIV-1 and BC

Next, we examined HIV-1 distribution within individual endocytic compartments of the BC. MDM were exposed to DiD- or DiO-labeled HIV-1 for $3 \mathrm{~h}$. Equivalent numbers of uninfected MDM were added and allowed to establish BC between adherent cells. Cells were then fixed and immunostained for endosome markers that included EEA1 for early endosomes, HLA-DR for MVB and LAMP1 for late endosomes/lysosomes. For tracking of HIV-1 with recycling endosomes, MDM were exposed to both fluorescently 

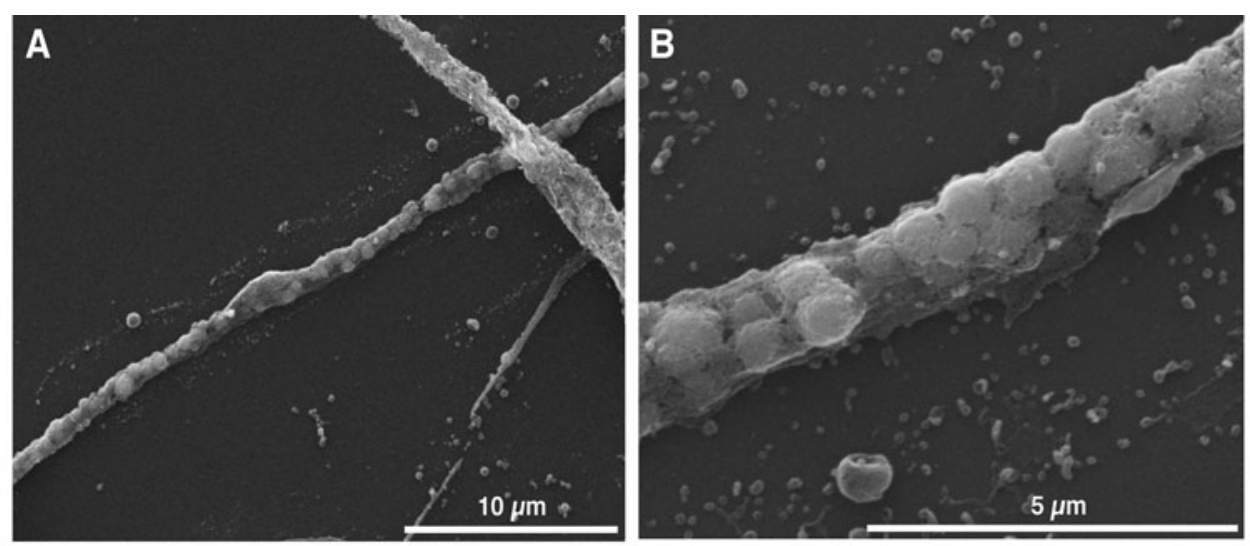

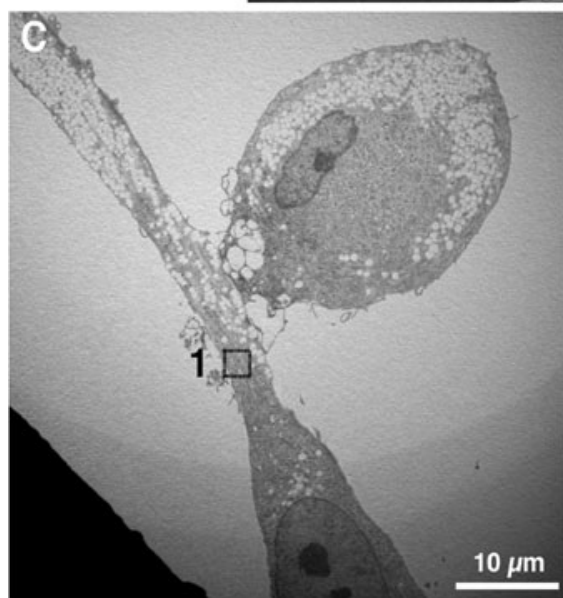

E

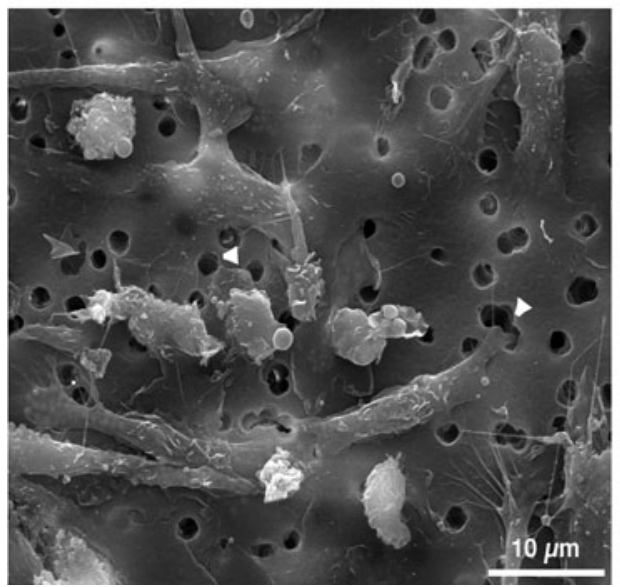

Fig. 3 Ultrastructural and biochemical characterization of BC. a, b SEM image of macrophage conduit reveals vesicle-like structures sheathed by plasma membrane. c TEM image of a sectioned conduit shows coated and uncoated vesicles of various sizes and electron densities, and large lipid droplets (inset 1 and 2, arrows). d TEM image of $\mathrm{BC}$ cross-sections generated from polarized MDM in mixed culture. Cells were immunostained for HIV-1 Gag. Secondary Ab conjugated to $6 \mathrm{~nm}$ gold particles was used for detection. Arrows (red) indicate endocytic compartments laden with gold particles. Rare

labeled HIV-1 and Tfn-Alexa Fluor 568. Fluorescently labeled HIV-1 was observed within multiple endocytic capsid-like dense structures were observed in endocytic vesicles (blue arrow). e SEM image of infected macrophages seeded in the upper chamber of a Boyden chemotaxis apparatus, extending their processes through a polycarbonate porous membrane towards the lower chamber (arrows). f Classification by function of the proteins identified with two or more significant $(P<0.05)$ and unique peptides in the $\mathrm{BC}$ proteome (pooled sample from five independent experiments). Refer also to Table S2 for a list of proteins identified in the conduits

compartments (Figure S4A-C). However, Pearson's colocalization test indicated preferential association of HIV-1 
with early $(68 \pm 2 \%)$, recycling endosomes $(57 \pm 4.1 \%)$ and MVB $(82 \pm 0.1 \%$; mean \pm S.E.M; Fig. S4A-C). Since, HIV1 uncoating can occur in early endosomes, tracking of fluorescently labeled HIV-1 (envelope-labeled with lipophilic dyes) into endocytic compartments may not reflect the fate of all viral constituents (Miyauchi et al. 2009). Therefore, we investigated endocytic sorting of each viral constituent (Env, Gag and RNA) separately. Similar to fluorescently labeled HIV-1, Env, Gag and RNA were readily identified within early endosomes, MVB, recycling endosomes (Rab11a) and lysosomes in the BC (Fig. 4a-k). CHMP4a was used as an MVB marker instead of HLA-DR, as HLA-DR is abundantly present in both the HIV-1 envelope and MVB (Ott et al. 2000). CHMP4a is a member of the endosomal-sorting complex required for transport (ESCRTIII) family, which together with tumor susceptibility gene 101 (Tsg101) regulates early endosome-to-MVB sorting and HIV-1 budding within MVB (Babst et al. 2002; Deneka et al. 2007; Welsch et al. 2007). Immunostaining for Rab11a, a regulator of fast (Tfn receptor) and slow endocytic recycling, was performed to expand detection of recycling endosome populations (Trischler et al. 1999). Metabolic labeling of RNA (cellular and viral) was chosen over FISH (gag-pol probes) since tissue degradation by proteinase $\mathrm{K}$ during FISH interferes with additional immunostaining for endocytic markers. Env, Gag and RNA were present at varying levels in $\mathrm{BC}$ endosomes. However, significant $(P<$ $0.05)$ levels of Env were seen within early and recycling endosomes (Fig. 41). Gag and RNA preferentially $(P<0.05)$ colocalized with MVB and Rab11 endosomes (Fig. 4m,n).

Intra- and intercellular trafficking of HIV-1 constituents in MVB-Rab11 recycling endosomes

Having identified Env, Gag and RNA in several endosome populations and their preferential distribution with recycling endosomes, we next queried whether HIV-1 sorting routes converged with the recycling pathway. Endosomes and lysosomes may undergo partial fusion with late and recycling endosomes to form temporary recycling hybrid compartments targeted for the plasma membrane (Blott and Griffiths 2002; Bright et al. 1997; Luzio et al. 2005). This process would explain the overlap in endocytic distribution of HIV-1. Indeed, partial colocalization of EEA1 $(54 \pm 2 \%)$, LAMP1 $(34 \pm 1 \%)$ and CHMP4a ( $34 \pm 2 \%$; mean \pm S.E.M., $n=80$ cells/group) was observed with $\mathrm{Rab}_{11^{+}}$compartments. In addition, endosomes carrying both early endosome and MVB markers were also identified (Figure S5AC). Disruption of MVB biogenesis using wortmannin (Gruenberg and Stenmark 2004) and endocytic recycling with BFA (Wang et al. 2001) caused aggregation of Gag in large perinuclear vacuoles and excluded Gag from the $\mathrm{BC}$ (Figure S5D, E). Collectively, these findings demonstrate
Fig. 4 Distribution of HIV-1 constituents with BC endocytic compartments. a-k Confocal images of MDM in mixed culture showing distribution of HIV-1 Env (red, panels a, c, d and blue, b), Gag (green, b and red, e-g), metabolically labeled RNA (red) with early endosomes (green), MVB (green), recycling endosomes (green), and lysosomes (green) identified in the conduits (scale bars, $10 \mu \mathrm{m}$; insets, $5 \mu \mathrm{m}$ ). l-n, Pearson's colocalization tests of HIV-1 Env, Gag and RNA distribution with BC endocytic compartments. Pearson's colocalization coefficients were converted to percent overlap between fluorophores (error bars \pm S.E.M., $n=80$ cells)

that dissemination of HIV-1 constituents through the conduits occurs within endosomes and is regulated primarily by the MVB-Rab11a recycling route.

\section{Endocytic compartments carry infectious virus}

Although intercellular transmission of retroviruses by cellular extensions has been estimated at 100-1,000 times faster than cell-free virus, it is unknown whether this mode of viral dissemination results in infection (Martin and Sattentau 2009; Sowinski et al. 2008). Previous studies have shown that HIV-1 sequestered within macrophage endocytic compartments is infectious (Pelchen-Matthews et al. 2003; Sharova et al. 2005). Therefore, we tested whether this was the case for endocytic compartments in polarized macrophages. MDM ( $>90 \%$ of cell tethered by BC) were mechanically disrupted and the endosome fraction was collected by sucrose gradient. Protein A/G magnetic beads conjugated with Ab to EEA1, CHMP4a, Rab11a Ab, and LAMP1 were incubated with the endosome fraction and isolated by magnetic separation (Fig. 5a). Protein A/G paramagnetic beads conjugated to pooled isotype control antibodies were used to preclude non-specific binding of other subcellular membranes. Enrichment of endocytic compartments was confirmed by TEM. Figure $5 \mathrm{~b}$ shows high electron density endosomes bound to a magnetic bead (inset 1 , arrows).

Next, we determined the viral load (HIV-1 RNA copies) in each isolated endosome population. COBAS Amplicor analysis showed endosomes carried high viral loads $\left(\sim 10^{4}\right.$ HIV-1 RNA copies/ $\mu$ g of Ab; Fig. 5c). Numbers of HIV-1 RNA copies were distinct for each endosome population (Fig. 5c). Rab11 endosomes displayed the highest viral load $\left(3.2 \times 10^{4} \mathrm{RNA}\right.$ copies/ $\mu \mathrm{g}$ of $\left.\mathrm{Ab}\right)$ further supporting the role of the recycling pathway in viral trafficking. HIV-1 viral load for the isotype control pool was at background level, thus excluding non-specific binding to other viruscontaining membranes. To establish infectivity of endocytic viral cargo, we used a TZM-bl reporter cell line, which contains an integrated copy of the B-gal gene under control of the HIV-1 promoter (Platt et al. 1998). In MDM connected by $\mathrm{BC}$, we and others have observed a seamless flow of endosomes between infected (DiO-labeled) and uninfected cells (DiD-labeled cells; Fig. S6A, B) (Onfelt et 

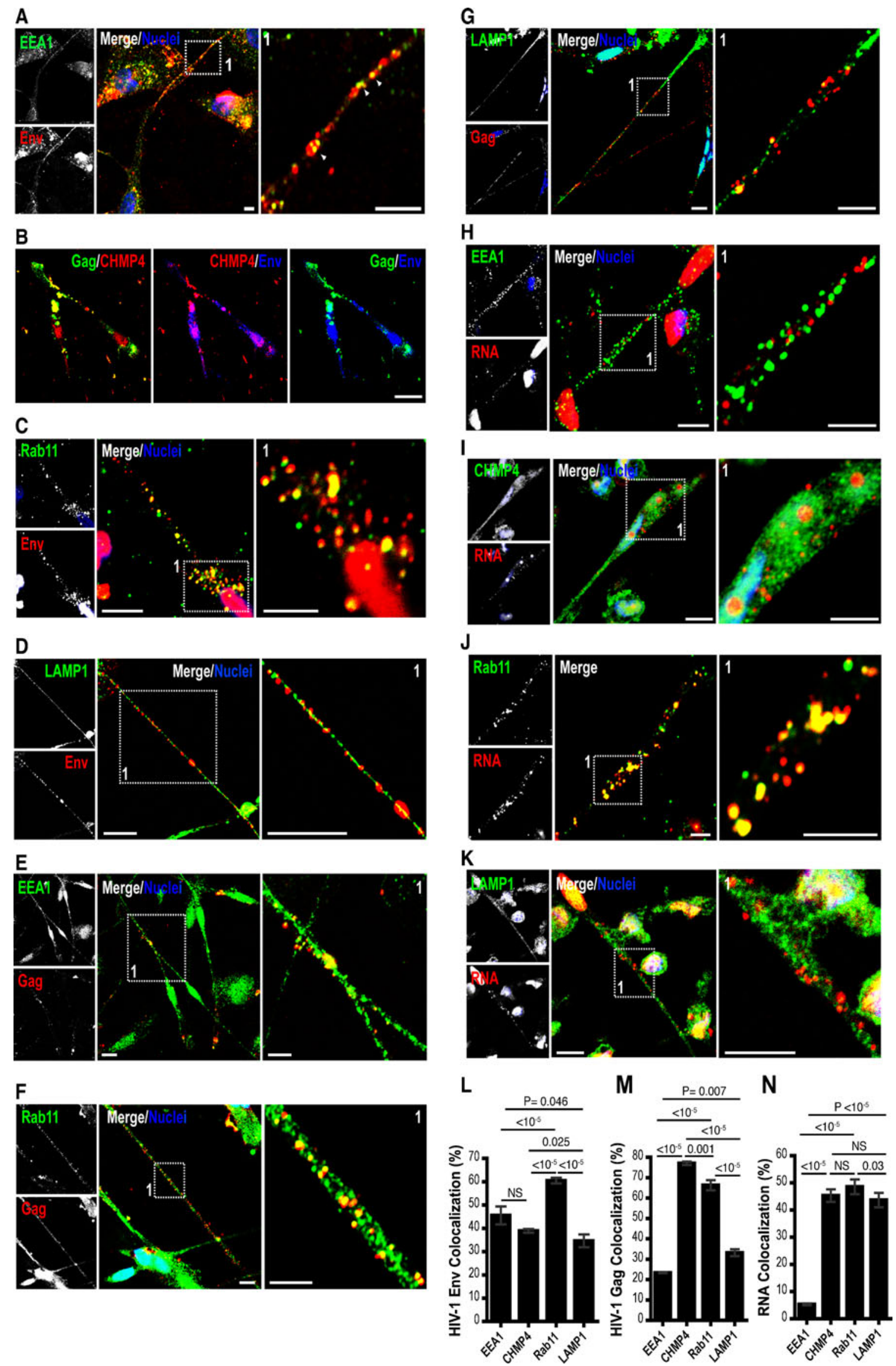
al. 2006). Upon reaching the target cells, endosomes either preserve their characteristics or fuse with native endosomes (encircled yellow). To test infectivity of endocytic cargoes, we mimicked direct access of endosomes to the intracellular milieu of the target cells. To accomplish this, we considered the following limitations: First, the TZM-bl reporter cell line has limited phagocytic characteristics and the immune isolated endosomes do not carry surface molecules (i.e., Fc receptors) necessary for internalization. Therefore, this excluded the possibility of receptor-mediated endocytosis as a mode of introducing the isolated compartments to the intracellular environment of TZM-bl. Second, isolated endosomes remain attached to the bulky magnetic beads $(10-15 \mu \mathrm{m}$ in diameter) that constituted a large cell entry barrier. Therefore, to gain access into the cytoplasm of the target cells (as it would occur via open-ended BC), endosome-bead complexes were forced into the TZM-bl by exposure to strong magnetic fields (Fig. 5a). Integration and expression of viral genome were confirmed by $\beta$-gal detection (blue) at $72 \mathrm{~h}$ post-exposure (Fig. 5d,e). Cells exposed to Rab11a and CHMP4a endosomes induced similar levels of $\beta$-gal as those observed with cell-free HIV-1 ( $P>$ $0.05)$. The infectivity of early endosomes and lysosomes was measured at significantly lower levels than cell-free HIV-1 $\left(P<0.001\right.$, Fig. 5g). Since, HIV-1 Tat ${ }^{+}$compartments were identified in the $\mathrm{BC}$, we questioned whether the expression of B-gal could be induced by Tat alone. TZM-bl were exposed to $2 \mu \mathrm{M}$ recombinant Tat for $24 \mathrm{~h}$ and then stained for B-gal. Tat treatment altered the cellular morphology of TZM-bl compared to untreated uninfected cells; however similar to control exposure, Tat alone did not induce B-gal expression (Fig. 5d). Pre-treatment of TZM-bl with EFZ (a non-nucleoside reverse transcriptase inhibitor) prior to endosome exposure significantly $(P<0.0001)$ reduced $\beta-$ gal expression (Fig. 5f,g). These findings indicate infectious viral cargoes are preserved within endosomes and are capable of inducing bona fide infections.

HIV-1 is transported through the $\mathrm{BC}$ in non-degrading endocytic compartments

Next, we examined the role of endosome transport in viral propagation. MDM labeled with $\mathrm{DiD}$ were exposed to fluorescently labeled HIV-1 and allowed to establish viral transfer through the conduits to the uninfected cells (Movie S6). Alternatively, cells exposed to DiO-HIV-1 were treated with CD, Noc and BBST. CD and Noc were tested for inhibition of endocytic transport due to involvement of actin tails and microtubules in the propulsion of endosomes (DePina and Langford 1999).

BBST, a non-muscle myosin II inhibitor, was used to test myosin II-dependent transport of viral constituents. Among the myosin isoforms identified in the $\mathrm{BC}$
Fig. 5 Endocytic compartments carry infectious viral cargo. a Illustration of immunoisolation of endocytic compartments from polarized MDM in mixed culture and their magnet-induced entry in TZM-bl reporter cell line. b TEM of enriched endocytic compartments bound to paramagnetic beads. Arrows indicate high-density endosomes. c HIV-1 viral load (RNA copies) in early endosomes, lysosomes, MVB and recycling endosomes and isotype control Abs. d, e Representative bright field images of uninfected TZM-bl, cells exposed to HIV-1 Tat, cell-free HIV-1, and immune-isolated endocytic compartments expressing different levels of $\beta$-gal (blue) at $72 \mathrm{~h}$ postexposure. Arrows indicate paramagnetic beads (brown) within TZMbl. f Representative images of TZM-bl showing susceptibility of cellfree and endocytic HIV-1 infection to antiretroviral treatment. $g$ Quantiation of overall endosome infectivity and susceptibility to antiretroviral therapy (efavirenz) in TZM-bl (scale bars $100 \mu \mathrm{m}$; error bars, \pm S.E.M., $n=400$ cells/group, $N=2$ independent experiments)

proteome, myosin II was further investigated due to its high co-distribution with viral proteins (Fig. 6a) and endocytic compartments (Fig. S7A-D). Cells exposed to HIV-1 alone and to CD, Noc or BBST were subjected to viral particle tracking analysis by still and time-lapse confocal imaging. Treatment with inhibitors induced aggregation of HIV-1 Env/Gag in the perinuclear region in CD- and Noc-treated MDM and large vacuoles in BBST-treated cells (Fig. 6b). In untreated cells the velocity of viral transfer averaged at $1.1 \pm 0.1 \mu \mathrm{m} \cdot \mathrm{s}^{1}$ (mean \pm S.E.M., $n=70$ particles). Exposure to CD, Noc, or BBST significantly suppressed endosome movement at each time point, including average velocity $(P<0.0001)$, path length $(P<0.0001)$ and displacement $(P<0.0001, n=$ 70 particles/group) compared to untreated cells (Fig. 6c-e). Together these findings demonstrate that cell-to-cell spread of HIV-1 through BC is dependent upon the integrity of endocytic and actin-myosin networks.

\section{Discussion}

We demonstrated that unlike other retroviruses that "surf" cellular protrusions, HIV-1 exploits endocytic traffic through bridging conduits for its intercellular spread. In previous studies, viral endocytic entry was shown to effect the viral life cycle (Martin and Sattentau 2009; Uchil and Mothes 2009). HIV-1 enters the cell by clathrin-mediated endocytosis and uncoating, occurs in endocytic compartments (Miyauchi et al. 2009). Indeed, genomic screens for host proteins required for infection demonstrate a dependency of HIV-1 replication on the integrity of the endocytic networks (Brass et al. 2008). HIV-1 intracellular endocytic trafficking is linked to viral assembly and budding. The latter occurs within the MVB and in the endoplasmic reticulum and Golgi membranes (Orenstein et al. 1988; Pelchen-Matthews et al. 2003). Although endolysosomal compartments are in $\mathrm{BC}$, specific endocytic pathways and endosome sub-types used for intra- and intercellular viral 
A

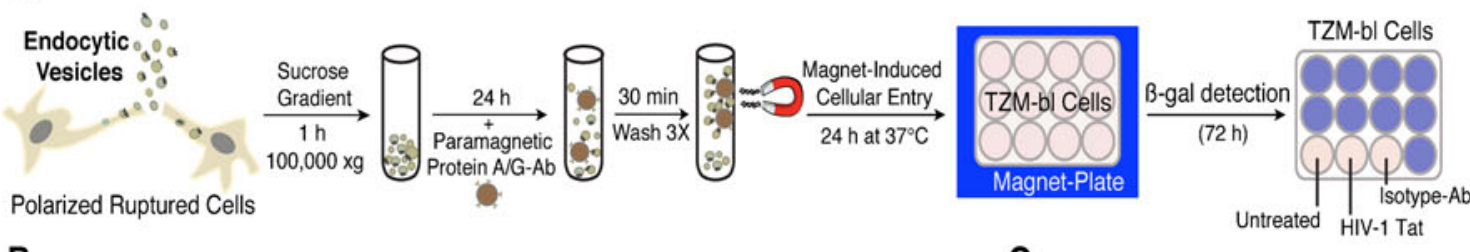

B
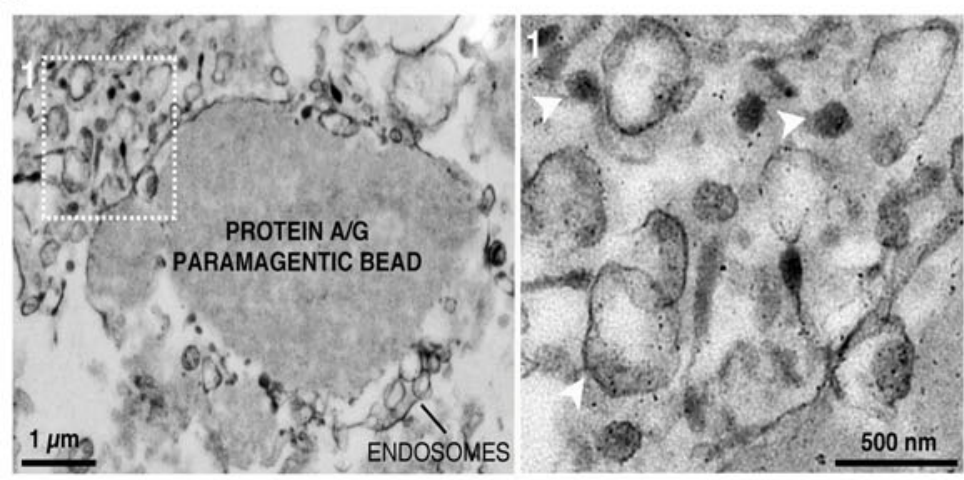

C

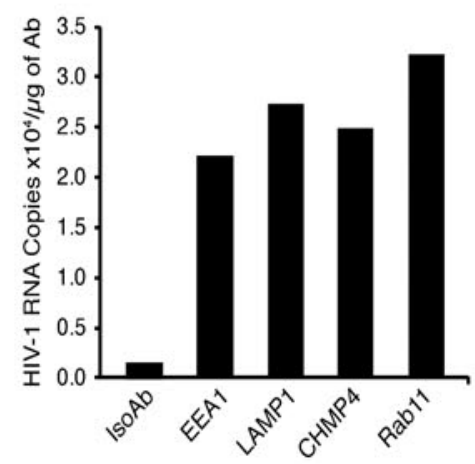

D

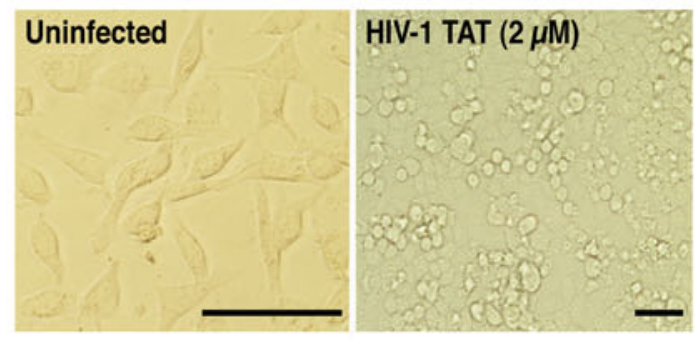

E
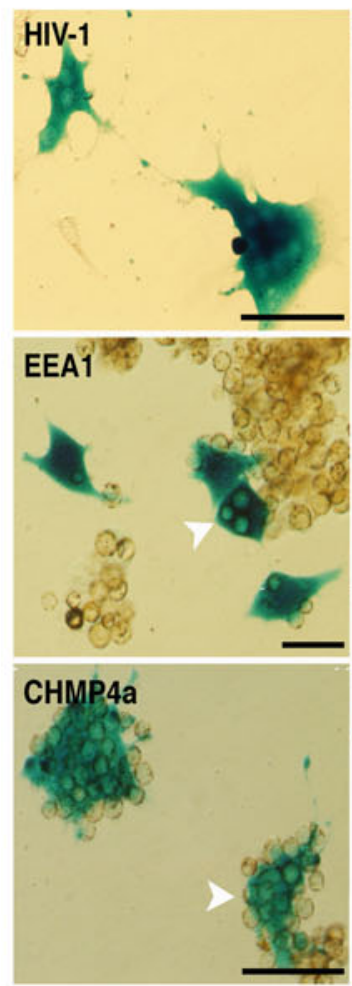

F
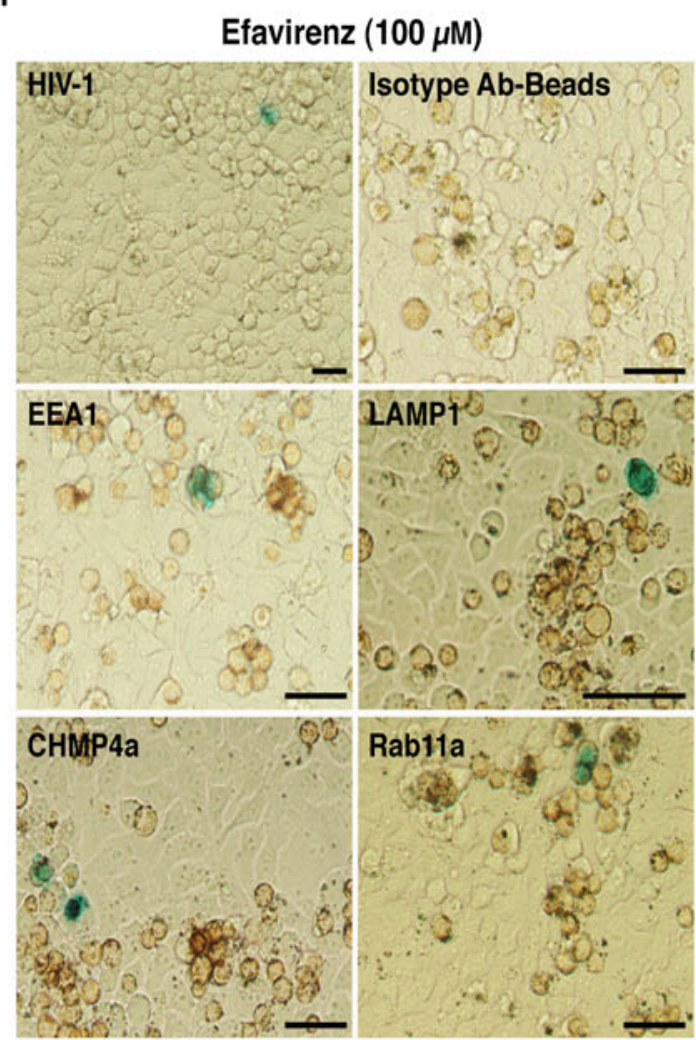

G

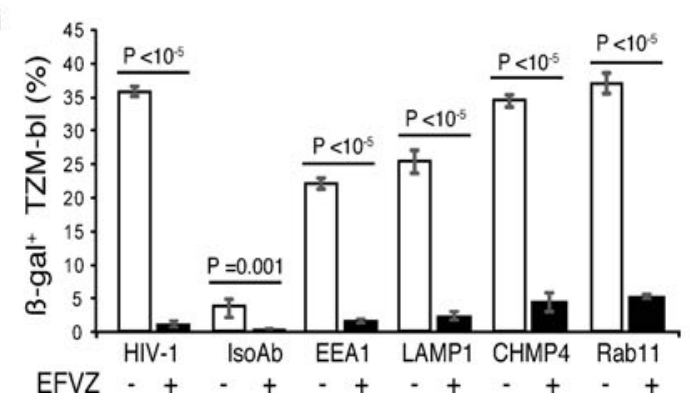


A

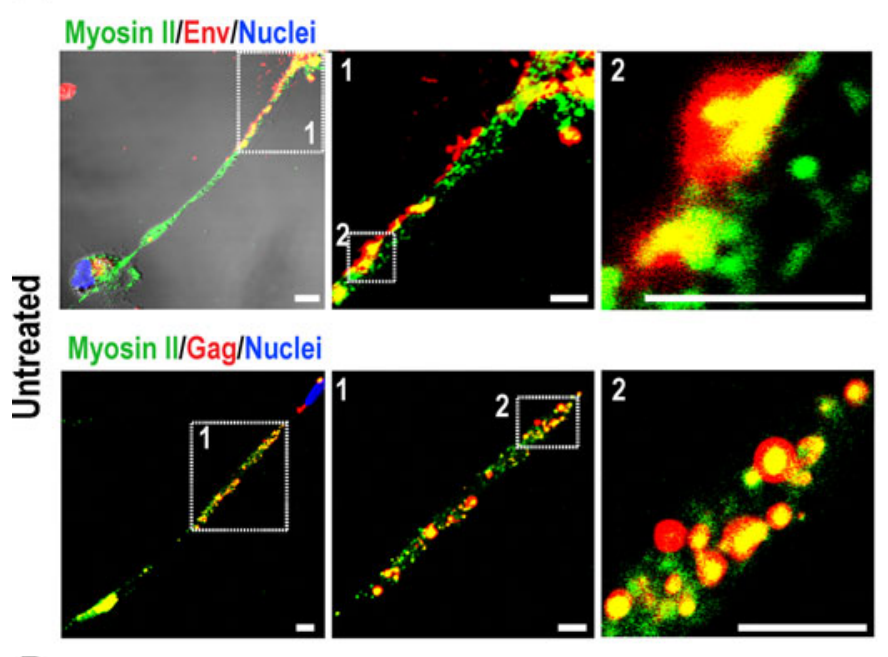

B
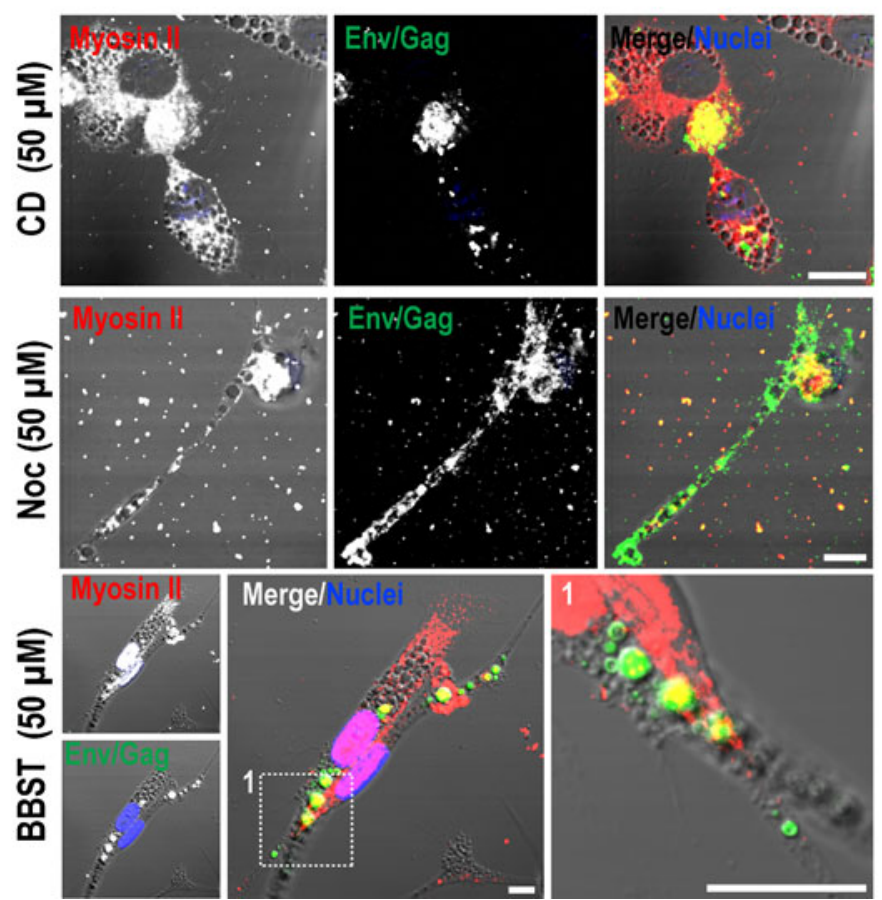

Fig. 6 Dependence of viral transfer on integrity of endocytic transport. a, b Distribution of myosin II with HIV-1 Env and Gag, in MDM untreated or exposed to CD, Noc or BBST post-formation of BC (scale bar, $10 \mu \mathrm{m})$. c-e Disruption of endosome/viral motility by $\mathrm{CD}$, Noc or BBST. Progressive average movement was determined

processing remained unknown (Rustom et al. 2004; Uchil and Mothes 2009) until now.

Herein, we explored intra- and intercellular HIV-1 macrophage endocytic trafficking routes. It is as follows. Intracellular transport begins with receptor binding and internalization into clathrin-coated pits. This is followed by viral recruitment into early sorting endosomes representing large tubular networks directing downstream endocytic
C

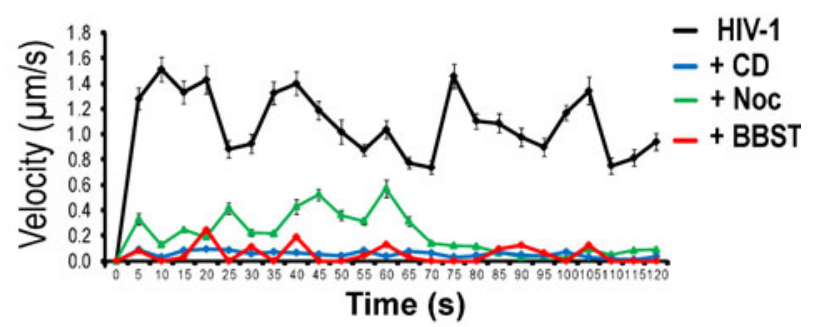

D

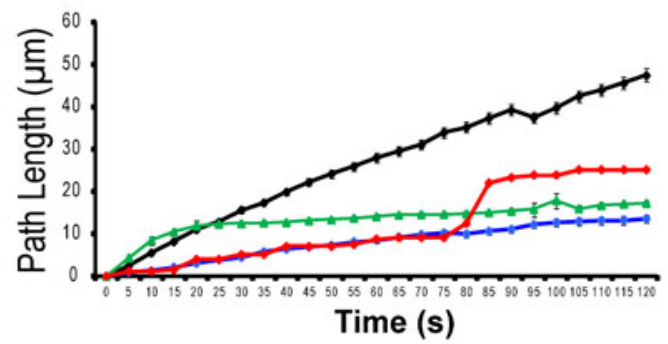

E

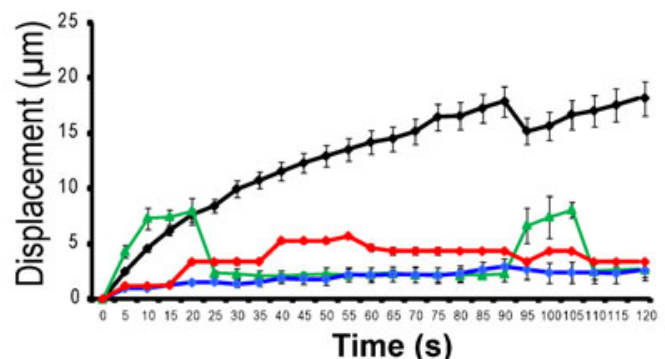

using the mean velocity $\left(\mu \mathrm{m} \bullet \mathrm{s}^{-1}\right)$, path length $(\mu \mathrm{m})$, and displacement from the origin for all analyzed particles (error bars, \pm S.E.M., $n=70$ particles/group, $N=3$ independent experiments) at each time point for $120 \mathrm{~s}$

sorting (Christoforidis et al. 1999; Maxfield and McGraw 2004). Viral uncoating may occur at this stage, explaining the absence of mature HIV-1 in the BC or within endocytic vesicles (Miyauchi et al. 2009). From the early sorting endosomes, viral constituents may undergo a range of processing routes and may be targeted to the MVB. These represent a subpopulation of late endosomes that serve as intermediate stations for recycling and secretion (de Gassart 
et al. 2004; Gruenberg and Stenmark 2004). HIV-1 may also undergo maturation here and then following fusion with Rab11 endosomes virus, is recruited to, and then released from the plasma membrane (Maxfield and McGraw 2004; Pelchen-Matthews et al. 2003). Possible back fusion of lysosomes and MVB with Rab11 compartments would explain viral targeting to MVB and "secretory" or non-degrading lysosomes. This is followed by viral trafficking to the plasma membrane where exosome and protein exocytosis occur (Maxfield and McGraw 2004; Pelchen-Matthews et al. 2003). Early endosomes may also fuse with Rab11 and be directed to the perinuclear region and into the endocytic recycling compartment (Maxfield and McGraw 2004). These can then target to the plasma membrane of effecter cells for HIV-1 assembly or transport through bridging conduits to uninfected cells. Such HIV-1 intra- and intercellular sorting pathways are summarized in Fig. 7.

What targets viral constituents to a neighboring cell requires further investigation. Previous studies demonstrated the presence of antigen-presenting MHCII-CD4 complexes and HIV-1 proteins in BC formed between macrophages, $\mathrm{B}$ cells and $\mathrm{T}$ cells in lymph nodes (Brown et al. 2008; Chinnery et al. 2008; Xu et al. 2009). Proteomic and confocal analyses also identified these proteins in the macrophage BC. Since HLA-DR is the most abundant protein in the HIV-1 Env, it is likely that processing of HIV-1 may be guided by CD4-HLA-DR endocytic

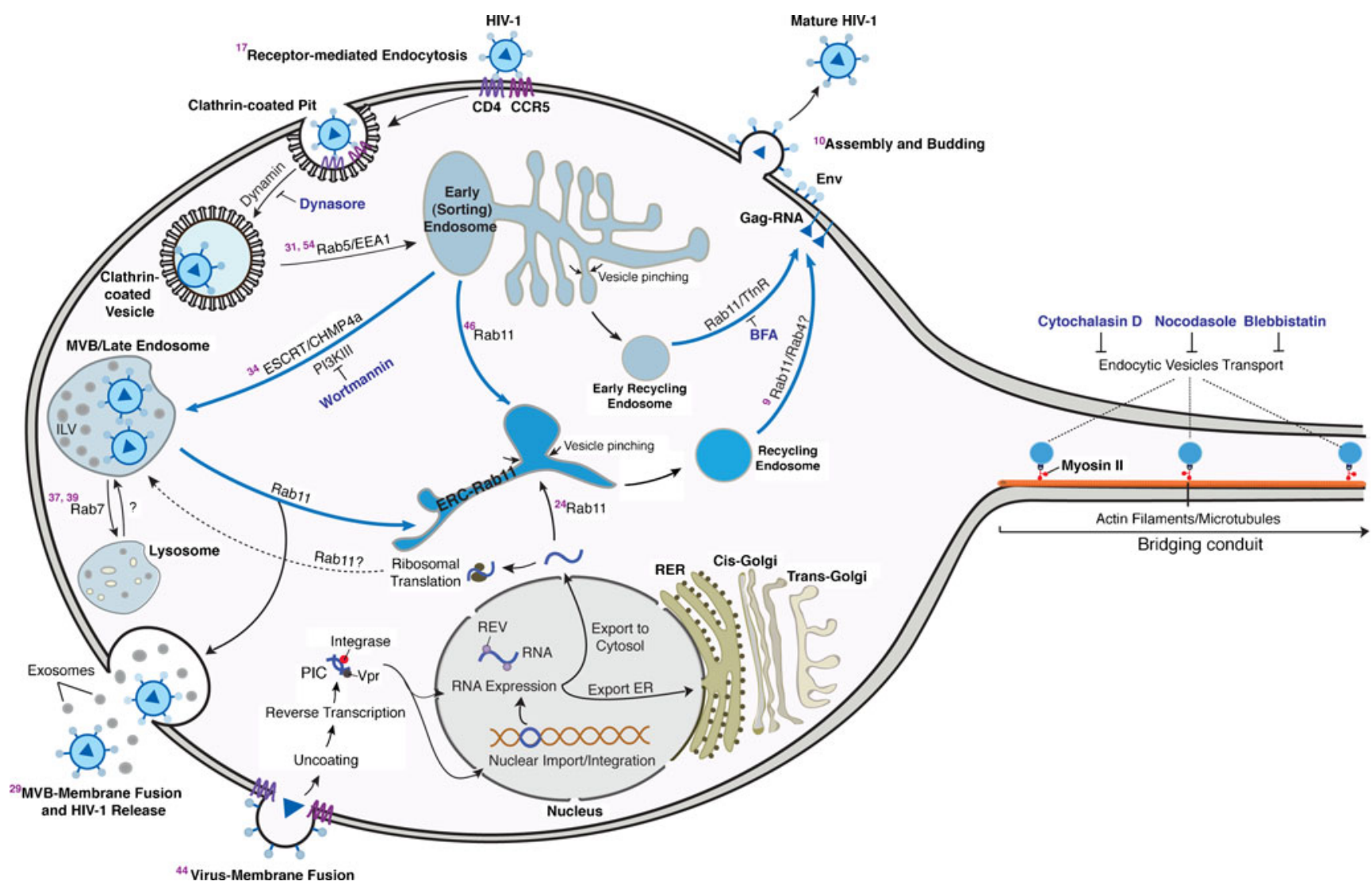

Fig. 7 Pathways of macrophage intra- and intercellular HIV-1 trafficking. HIV-1 receptor-mediated entry is regulated by clathrincoated pits (Miyauchi et al. 2009). Upon inhibition of dynamin by dynasore, viral entry is blocked. Clathrin-coated vesicles containing HIV-1 may undergo Rab5/EEA1-dependant fusion with the early sorting endosome(Bucci et al. 1992; Zerial and McBride 2001). Endosomes can pinch off the vesiculo-tubular network also termed early sorting endosome (Maxfield and McGraw 2004) and undergo the following downstream sorting routes: a fuse with the endocytic recycling compartment (ERC; perinuclear region) and then undergo Tfn-like Rab11-mediated recycling to the $\mathrm{BC}$ and plasma membrane (Maxfield and McGraw 2004). Disruption of this processes by brefeldin A results in accumulation of HIV-1 constituents in large cytosolic compartments (Wang et al. 2001). b undergo sorting to the MVB for ILV biogenesis, virus assembly and budding regulated by
ESCRT family (Babst et al. 2002; Garrus et al. 2001; Gill et al. 2007). MVB in turn may undergo fusion with Rab11 endosomes to be transported either to the plasma membrane for exosomal release (Simons and Raposo 2009) or intercellular transfer through the conduits. Disruption of MVB biogenesis by wortmannin results in agregation of HIV-1 constituents in large vaccuoles (Gruenberg and Stenmark 2004). Lysosomes may undergo backfusion with MBV and Rab11 compartments to be targeted at the plasma membrane (secretory non-degrading lysosomes; (Blott and Griffiths 2002; Luzio et al. 2005) or the bridging conduits. In parallel to endocytic entry and intercellular trafficking, virion-plasma membrane fusion may also occur followed by uncoating, reverse trancription, formation of preintegration complexes (PIC), and RNA expression (Brass et al. 2008). Thick blue arrows indicate trafficking routes that target HIV-1 directly to the conduits 
processing (Callahan et al. 1993; Ott et al. 2000). This could explain similarities in HLA-DR processing routes and trafficking of viral constituents within MVB recycling compartments (Fernandes et al. 2000; Raposo et al. 2002; Romagnoli et al. 1993). These processes may be relevant for viral spread in vivo. HIV-1 may exploit the high mobility and antigen presentation characteristics of macrophages as a "Trojan Horse" for immune escape and dissemination.

Equally important issues remain; such as, can infectious virus be transmitted ell-to-cell from within endocytic compartments and does this mode of viral transfer result in the productive infection? MVB are likely infectious (Pelchen-Matthews et al. 2003). Our works demonstrate that in addition to MVB, which may carry HIV-1, early and recycling endosomes and lysosomes also transmit viral RNA and proteins. Regardless of abundant presence of HIV-1 constituents and RNA within endosomes, we were unable to identify mature HIV-1 within BC and immune isolated endosomes. Mature HIV-1 was frequently observed in the extracellular space. Instead, high-density endocytic compartments were easily identified and those carrying capsid-like structures were rarely observed. Although we performed extensive TEM analysis, we do not exclude the possibility that $\mathrm{BC}$ endocytic compartments could also carry mature HIV-1. However, there was a discrepancy between the viral loads and infectivity of endocytic compartments as well as our inabilities to observe mature virus by ultrastructural tests. We posit that a potential alternate route of HIV-1 dissemination and productive infection through the conduits could exist. This would involve sequestration of HIV-1 in endocytic compartments followed by uncoating and content mixing (Miyauchi et al. 2009). These viral cargoes would then be shuttled to uninfected target cells where viral components, although disassembled, could be capable of initiating infection.

If this were the case, then how is viral material unloaded from the endosomes to the cytosol of target cells? Recent studies on the MLV replication cycle have shown that Rab11 endosomes carrying MLV RNA have the ability to fuse with or bud from the cytosol either to release RNA in proximity to the nucleus or transport newly synthesized viral RNA to the plasma membrane (Basyuk et al. 2003). Similar to MLV, our data show that HIV-1 and cellular RNA primarily traffick within and between cells by Rab11 recycling endosomes. This would also explain how viral material gains access to effector cell endosomes and to target cell cytosol via BC. In addition to the relay of viral constituents by direct endosome-endosome fusion (clathrin pits-early endosomesearly endosomes-recycling endosomes or MVB-recycling endosomes), it is likely that budding and fusion of Rab11 with the cytosol allow loading of newly synthesized and original viral constituents into endosomes along with subsequent unloading into uninfected cells via BC-mediated transport. This process may be facilitated by seamless flow of endocytic compartments between BC-connected cells. Indeed, we observed that upon reaching the target cells, endosome transport was not interrupted and these compartments either fused with autochthonous endocytic compartments or preserved their original membranes. Additionally, connected polarized cells were observed to share organelles such as ER and Golgi (our unpublished observations). Formation of a cellular network that precedes and can lead to syncytium formation may allow the connected cells to function as a unicellular organism (Kadiu et al. 2007). Therefore, processes of viral assembly, maturation, release (in the effecter cell) as well as entry, and disassembly (in the target cells) are voided, thus reducing both transfer time and exposure to the host immune system (Martin and Sattentau 2009). Nonetheless, the infectivity of disassembled virus has not been previously reported. Processing of viral constituents into overlapping, yet different sorting routes suggests such a mode of viral transfer may exist and represents a barrier in designing efficient and targeted therapeutic strategies against HIV-1 infection.

Alternatively, HIV-1 may be trafficked from cell to cell within endosomes. We posit that four potential mechanisms may account for intercellular transfer of virus. First, MDM become productively infected, and newly synthesized virus gains access to intracellular membranes of neighboring cells where they are assembled and then transported to uninfected cells. This is however not very likely to occur since metabolic tracing of newly synthesized HIV-1 Env and Gag revealed targeting of these proteins to the plasma membrane rather than the conduits (our unpublished observations). Second, HIV-1 could be internalized by a polarized macrophage during secondary infection or "superninfection". Internalized virus may be then directly "recycled" to adjacent cells. Third, macrophages could "archive" mature HIV-1 progeny in endocytic compartments and upon contact, transfer HIV1-containing compartments through $\mathrm{BC}$ to uninfected cells. Fourth, although HIV-1 was distributed primarily with non-degrading compartments, we cannot exclude the possibility that transfer of HIV-1 to the uninfected cell may be driven by apoptosis of the effecter cells. Natural killer cells use conduits as a means for transfer of apoptotic bodies from dying cells (Chauveau et al. 2010). A similar process may occur in macrophages, as a function of their phagocytic and debris clearing activities. Although, low levels of cell death were measured in polarized MDM mixed cultures (our unpublished observations), uninfected MDM were often observed to form contacts with multinucleated giant cells. Therefore 
it is likely that endocytosed HIV-1 or progeny assembling in intracellular membranes during the initial stages of cell death may exploit transport of apoptotic bodies through the conduits as a means of survival. We posit that transmission of replication competent virus and transfer of viral constituents could occur in tandem. The processes that drive HIV-1 intercellular transfer by direct cell-cell contact nonetheless requires further investigation. Whether or not alternative transfer of viral constituents facilitate the viral life cycle or perhaps incite infection remains an open question.

Acknowledgements We thank Drs. R. L. Mosley, H. S. Fox and R. Taylor for the critical reading of the manuscript. We would like to acknowledge Dr. F. Kieken, F. Robert for bioinformatics support; T. Bargar, J. Taylor for their assistance with electron and confocal microscopy, B. Wassom for graphic design of the elements in Figure S8. This work was supported in part by National Institutes of Health grants P20 DA026146, 5P01 DA028555-02, R01 NS36126, P01 NS31492, 2R01 NS034239, P20 RR15635, P01 MH64570, and P01 NS43985 (to H.E.G). The authors declare no competing financial interests.

Open Access This article is distributed under the terms of the Creative Commons Attribution Noncommercial License which permits any noncommercial use, distribution, and reproduction in any medium, provided the original author(s) and source are credited.

\section{References}

Babst M, Katzmann DJ, Estepa-Sabal EJ, Meerloo T, Emr SD (2002) Escrt-III: an endosome-associated heterooligomeric protein complex required for mvb sorting. Dev Cell 3:271-282

Basyuk E, Galli T, Mougel M, Blanchard JM, Sitbon M, Bertrand E (2003) Retroviral genomic RNAs are transported to the plasma membrane by endosomal vesicles. Dev Cell 5:161-174

Beckner ME, Chen X, An J, Day BW, Pollack IF (2005) Proteomic characterization of harvested pseudopodia with differential gel electrophoresis and specific antibodies. Lab Invest 85:316-327

Blott EJ, Griffiths GM (2002) Secretory lysosomes. Nat Rev Mol Cell Biol 3:122-131

Bolte S, Cordelieres FP (2006) A guided tour into subcellular colocalization analysis in light microscopy. J Microsc 224:213232

Brass AL, Dykxhoorn DM, Benita Y, Yan N, Engelman A, Xavier RJ, Lieberman J, Elledge SJ (2008) Identification of host proteins required for HIV infection through a functional genomic screen. Science 319:921-926

Bright NA, Reaves BJ, Mullock BM, Luzio JP (1997) Dense core lysosomes can fuse with late endosomes and are re-formed from the resultant hybrid organelles. J Cell Sci 110(Pt 17):2027-2040

Brown K, Sacks SH, Wong W (2008) Extensive and bidirectional transfer of major histocompatibility complex class II molecules between donor and recipient cells in vivo following solid organ transplantation. FASEB J 22:3776-3784

Bucci C, Parton RG, Mather IH, Stunnenberg H, Simons K, Hoflack B, Zerial M (1992) The small GTPase rab5 functions as a regulatory factor in the early endocytic pathway. Cell 70:715-728

Callahan KM, Rowell JF, Soloski MJ, Machamer CE, Siliciano RF (1993) HIV-1 envelope protein is expressed on the surface of infected cells before its processing and presentation to class IIrestricted T lymphocytes. J Immunol 151:2928-2942

Chauveau A, Aucher A, Eissmann P, Vivier E, Davis DM (2010) Membrane nanotubes facilitate long-distance interactions between natural killer cells and target cells. Proc Natl Acad Sci USA 107:5545-5550

Chinnery HR, Pearlman E, McMenamin PG (2008) Cutting edge: membrane nanotubes in vivo: a feature of MHC class II + cells in the mouse cornea. J Immunol 180:5779-5783

Christoforidis S, McBride HM, Burgoyne RD, Zerial M (1999) The Rab5 effector EEA1 is a core component of endosome docking. Nature 397:621-625

Ciborowski P, Gendelman HE (2006) Human immunodeficiency virus-mononuclear phagocyte interactions: emerging avenues of biomarker discovery, modes of viral persistence and disease pathogenesis. Curr HIV Res 4:279-291

de Gassart A, Geminard C, Hoekstra D, Vidal M (2004) Exosome secretion: the art of reutilizing nonrecycled proteins? Traffic 5:896-903

Deneka M, Pelchen-Matthews A, Byland R, Ruiz-Mateos E, Marsh M (2007) In macrophages, HIV-1 assembles into an intracellular plasma membrane domain containing the tetraspanins CD81, CD9, and CD53. J Cell Biol 177:329-341

DePina AS, Langford GM (1999) Vesicle transport: the role of actin filaments and myosin motors. Microsc Res Tech 47:93-106

Dixit R, Tiwari V, Shukla D (2008) Herpes simplex virus type 1 induces filopodia in differentiated P19 neural cells to facilitate viral spread. Neurosci Lett 440:113-118

Eilbott DJ, Peress N, Burger H, LaNeve D, Orenstein J, Gendelman HE, Seidman R, Weiser B (1989) Human immunodeficiency virus type 1 in spinal cords of acquired immunodeficiency syndrome patients with myelopathy: expression and replication in macrophages. Proc Natl Acad Sci USA 86:3337-3341

Eugenin EA, Gaskill PJ, Berman JW (2009a) Tunneling nanotubes (TNT) are induced by HIV-infection of macrophages: a potential mechanism for intercellular HIV trafficking. Cell Immunol 254:142-148

Eugenin EA, Gaskill PJ, Berman JW (2009b) Tunneling nanotubes (TNT): a potential mechanism for intercellular HIV trafficking. Commun Integr Biol 2:243-244

Fernandes DM, Vidard L, Rock KL (2000) Characterization of MHC class II-presented peptides generated from an antigen targeted to different endocytic compartments. Eur J Immunol 30:2333-2343

Garrus JE, von Schwedler UK, Pornillos OW, Morham SG, Zavitz KH, Wang HE, Wettstein DA, Stray KM, Cote M, Rich RL, Myszka DG, Sundquist WI (2001) Tsg101 and the vacuolar protein sorting pathway are essential for HIV-1 budding. Cell 107:55-65

Gendelman HE, Orenstein JM, Martin MA, Ferrua C, Mitra R, Phipps T, Wahl LA, Lane HC, Fauci AS, Burke DS et al (1988) Efficient isolation and propagation of human immunodeficiency virus on recombinant colony-stimulating factor 1-treated monocytes. J Exp Med 167:1428-1441

Gerdes HH, Bukoreshtliev NV, Barroso JF (2007) Tunneling nanotubes: a new route for the exchange of components between animal cells. FEBS Lett 581:2194-2201

Gill DJ, Teo H, Sun J, Perisic O, Veprintsev DB, Emr SD, Williams RL (2007) Structural insight into the ESCRT-I/-II link and its role in MVB trafficking. EMBO J 26:600-612

Gousset K, Schiff E, Langevin C, Marijanovic Z, Caputo A, Browman DT, Chenouard N, de Chaumont F, Martino A, Enninga J, Olivo-Marin JC, Mannel D, Zurzolo C (2009) Prions hijack tunnelling nanotubes for intercellular spread. Nat Cell Biol $11: 328-336$

Gruenberg J, Stenmark H (2004) The biogenesis of multivesicular endosomes. Nat Rev Mol Cell Biol 5:317-323 
Jouve M, Sol-Foulon N, Watson S, Schwartz O, Benaroch P (2007) HIV-1 buds and accumulates in "nonacidic" endosomes of macrophages. Cell Host Microbe 2:85-95

Kadiu I, Gendelman HE (2011) Macrophage bridging conduit trafficking of HIV-1 through the endoplasmic reticulum and Golgi network. J Proteome Res 10(7):3225-3238

Kadiu I, Ricardo-Dukelow M, Ciborowski P, Gendelman HE (2007) Cytoskeletal protein transformation in HIV-1-infected macrophage giant cells. J Immunol 178:6404-6415

Kadiu I, Wang T, Schlautman JD, Dubrovsky L, Ciborowski P, Bukrinsky M, Gendelman HE (2009) HIV-1 transforms the monocyte plasma membrane proteome. Cell Immunol 258:44-58

Lundquist EA (2009) The finer points of filopodia. PLoS Biol 7: e1000142

Luzio JP, Pryor PR, Gray SR, Gratian MJ, Piper RC, Bright NA (2005) Membrane traffic to and from lysosomes. Biochem Soc Symp 72:77-86

Martin N, Sattentau Q (2009) Cell-to-cell HIV-1 spread and its implications for immune evasion. Curr Opin HIV AIDS 4:143-149

Maxfield FR, McGraw TE (2004) Endocytic recycling. Nat Rev Mol Cell Biol 5:121-132

Miyauchi K, Kim Y, Latinovic O, Morozov V, Melikyan GB (2009) HIV enters cells via endocytosis and dynamin-dependent fusion with endosomes. Cell 137:433-444

Onfelt B, Nedvetzki S, Benninger RK, Purbhoo MA, Sowinski S, Hume AN, Seabra MC, Neil MA, French PM, Davis DM (2006) Structurally distinct membrane nanotubes between human macrophages support long-distance vesicular traffic or surfing of bacteria. J Immunol 177:8476-8483

Orenstein JM, Meltzer MS, Phipps T, Gendelman HE (1988) Cytoplasmic assembly and accumulation of human immunodeficiency virus types 1 and 2 in recombinant human colony-stimulating factor-1-treated human monocytes: an ultrastructural study. J Virol 62:2578-2586

Ott DE, Coren LV, Johnson DG, Kane BP, Sowder RC 2nd, Kim YD, Fisher RJ, Zhou XZ, Lu KP, Henderson LE (2000) Actin-binding cellular proteins inside human immunodeficiency virus type 1 . Virology 266:42-51

Pelchen-Matthews A, Kramer B, Marsh M (2003) Infectious HIV-1 assembles in late endosomes in primary macrophages. J Cell Biol 162:443-455

Platt EJ, Wehrly K, Kuhmann SE, Chesebro B, Kabat D (1998) Effects of CCR5 and CD4 cell surface concentrations on infections by macrophagetropic isolates of human immunodeficiency virus type 1. J Virol 72:2855-2864

Raposo G, Moore M, Innes D, Leijendekker R, Leigh-Brown A, Benaroch P, Geuze H (2002) Human macrophages accumulate HIV-1 particles in MHC II compartments. Traffic 3:718-729
Romagnoli P, Layet C, Yewdell J, Bakke O, Germain RN (1993) Relationship between invariant chain expression and major histocompatibility complex class II transport into early and late endocytic compartments. J Exp Med 177:583-596

Rustom A, Saffrich R, Markovic I, Walther P, Gerdes HH (2004) Nanotubular highways for intercellular organelle transport. Science 303:1007-1010

Sharova N, Swingler C, Sharkey M, Stevenson M (2005) Macrophages archive HIV-1 virions for dissemination in trans. EMBO J 24:2481-2489

Sherer NM, Mothes W (2008) Cytonemes and tunneling nanotubules in cell-cell communication and viral pathogenesis. Trends Cell Biol 18:414-420

Sherer NM, Lehmann MJ, Jimenez-Soto LF, Horensavitz C, Pypaert M, Mothes W (2007) Retroviruses can establish filopodial bridges for efficient cell-to-cell transmission. Nat Cell Biol 9:310-315

Simons M, Raposo G (2009) Exosomes-vesicular carriers for intercellular communication. Curr Opin Cell Biol

Sowinski S, Jolly C, Berninghausen O, Purbhoo MA, Chauveau A, Kohler K, Oddos S, Eissmann P, Brodsky FM, Hopkins C, Onfelt B, Sattentau Q, Davis DM (2008) Membrane nanotubes physically connect $\mathrm{T}$ cells over long distances presenting a novel route for HIV-1 transmission. Nat Cell Biol 10:211219

Trischler M, Stoorvogel W, Ullrich O (1999) Biochemical analysis of distinct Rab5- and Rab11-positive endosomes along the transferrin pathway. J Cell Sci 112(Pt 24):4773-4783

Uchil PD, Mothes W (2009) HIV entry revisited. Cell 137:402-404

Vonna L, Wiedemann A, Aepfelbacher M, Sackmann E (2007) Micromechanics of filopodia mediated capture of pathogens by macrophages. Eur Biophys J 36:145-151

Wang JJ, Sandefur S, Spearman P, Chiou CT, Chiang PH, Ratner L (2001) Tracking the assembly pathway of human immunodeficiency virus type $1 \mathrm{Gag}$ deletion mutants by immunogold labeling. Appl Immunohistochem Mol Morphol 9:371-379

Welsch S, Keppler OT, Habermann A, Allespach I, Krijnse-Locker J, Krausslich HG (2007) HIV-1 buds predominantly at the plasma membrane of primary human macrophages. PLoS Pathog 3:e36

Xu W, Santini PA, Sullivan JS, He B, Shan M, Ball SC, Dyer WB, Ketas TJ, Chadburn A, Cohen-Gould L, Knowles DM, Chiu A, Sanders RW, Chen K, Cerutti A (2009) HIV-1 evades virus-specific $\mathrm{IgG} 2$ and $\mathrm{IgA}$ responses by targeting systemic and intestinal B cells via long-range intercellular conduits. Nat Immunol 10:1008-1017

Zerial M, McBride H (2001) Rab proteins as membrane organizers. Nat Rev Mol Cell Biol 2:107-117 